\title{
Unprecedented Coumarin-Pyronin Hybrid Dyes: Synthesis, Fluorescence Properties and Theoretical Calculations
}

\author{
Kévin Renault, ${ }^{*}[a]$ Arnaud Chevalier, ${ }^{[b]}$ Jérôme Bignon, ${ }^{[b]}$ Denis Jacquemin, ${ }^{*[c]}$ Jean-Alexandre Richard, ${ }^{[d]}$ \\ and Anthony Romieu ${ }^{*}[a]$
}

\begin{abstract}
A novel class of rosamine dyes bearing a 7-substituted 4-hydroxycoumarin unit as meso-heteroaryl ring is presented. The latent $C$-nucleophilic character of 4-hydroxycoumarin derivatives (i.e., their $\mathrm{C}$-3 position as nucleophilic center) has been drawn on in the designing of two unprecedented synthetic routes towards these atypical xanthene dyes. They are based on an effective formal Knoevenagel condensation with either pyronin derivatives or a mixed bis-aryl ether bearing both an aldehyde and a masked phenylogous amine, possibly applicable to a wide range of latent cyclic $C$-nucleophiles. We also report experimental and theoretical photophysical investigations of these unique coumarin-pyronin hybrid structures and particularly their form low-lying quenching states, some of dark twisted intramolecular charge transfer (TICT) nature, depending on the medium $\left(\mathrm{CHCl}_{3}\right.$ and water). Furthermore, two fluorophore compounds $\mathbf{9}$ and $\mathbf{1 1}$ have been applied for imaging in paraformaldehyde-fixed A549 cells to gain insights into their permeation and localization.
\end{abstract}

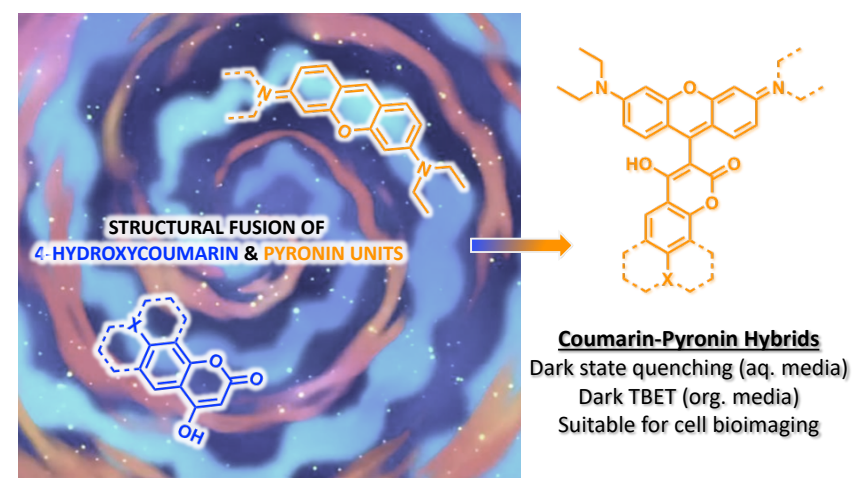

[a] Dr. K. Renault, Prof. A. Romieu ICMUB, UMR 6302, CNRS Univ. Bourgogne Franche-Comté 9, Avenue Alain Savary 21000 Dijon (France)

E-mail: kevin.renault@u-bourgogne.fr or anthony.romieu@u-bourgogne.fr Homepage: http://www.icmub.com

[b] Dr. A. Chevalier, Dr. J. Bignon Institut de Chimie des Substances Naturelles, CNRS UPR 2301 Université Paris-Saclay

1, Avenue de la Terrasse

91198 Gif-sur-Yvette (France)

E-mail: arnaud.chevalier@cnrs.fr or jerome.bignon@cnrs.fr

[c] Prof. D. Jacquemin

CEISAM Lab, UMR 6230

Université de Nantes, CNRS, F-44000 Nantes (France)

E-mail: Denis.Jacquemin@univ-nantes.fr

[d] Dr. J.-A. Richard

Functional Molecules and Polymers, Institute of Chemical and Engineering Sciences (ICES)

Agency for Science, Technology and Research (A*STAR)

8 Biomedical Grove, Neuros, \#07-01

Singapore 138665

Present address: Research and Technology Development, Illumina,

29 Woodlands Industrial Park E1, Singapore 757716

E-mail: jeanalexandre.richard@illumina.com

Supporting information for this article is given via a link at the end of the document.

\section{Introduction}

Since their discovery in the late $19^{\text {th }}$ century by the Swiss chemist Maurice Ceresole through the first syntheses of rhodamine $B$ and its tetramethyl analog (known as TMR or TAMRA $)^{[1]}$, rhodamine dyes have become one of the most valuable classes of visible range fluorophores. Indeed, the unique attributes of these xanthene molecules such as (1) high brightness both in organic and aqueous media, (2) excellent photostability and outstanding chemical stability under harsh conditions of $\mathrm{pH}$ and temperature, and (3) easy tuning of fluorescence emission through the spiro-cyclization based mechanism or through the reversible "capping" of primary/secondary aniline moieties, make them attractive fluorescent labels in a myriad of applications, especially those related to (bio)analytical and sensor sciences. ${ }^{[2]}$ Some remarkable achievements, especially in challenging biological contexts, were made possible by innovative structural optimization strategies that provide a wide range of high performance rhodamine-inspired molecules with optimal spectral properties and/or fluorogenic behavior, typically within the farred or near-infrared (NIR) spectral range (e.g., rosamines ${ }^{[3]}$ and rhodols $^{[4]}$, hetero-rhodamines and related hetero-xanthenes, as well as hybrids with other fluorophore scaffolds ${ }^{[5]}$ ). Among the different approaches currently implemented to modulate the fluorescence of the pyronin unit (i.e., the core structure of 
rhodamine dyes), one based on changes in the substitution pattern of the meso-(2-carboxyphenyl) ring or its replacement by another heteroaryl or related exotic substituent, for fine-tuning redox potential and thereby promoting reductive or oxidative photoinduced electron transfer $(\mathrm{PeT})$ process, has shown its full potential for designing analyte-responsive fluorogenic probes for biosensing and bioimaging. ${ }^{[6]}$ Given the wide range of (hetero)aryl groups explored as substitutes of meso-(2carboxyphenyl) moiety, it is surprising, though, that little attention was paid to fluorescent heterocycles (e.g., 7-(dialkylamino)- or 7hydroxycoumarins and their aza-anologs namely carbostyril dyes). Indeed, the facile tuning of their structural-electronic features should facilitate the implementation of a single or several interplaying photophysical processes (e.g., PeT, intramolecular charge transfer (ICT), twisted intramolecular charge transfer (TICT), excited state intramolecular proton transfer (ESIPT), Förster resonance energy transfer (FRET), through-bond energy transfer (TBET), ... $)^{[2 a-d, 2 f],[7]}$ that are all well recognized to strongly impact their emissive properties and/or those of the neighboring xanthene core. To the best of our knowledge, the sole examples of coumarin-rhodamine (or rosamine) hybrid structures are photoactive dyads bearing an electronically conjugated spacer (i.e., phenyl or phenylethynyl) between the donor and acceptor units and therefore acting as TBET ratiometric platforms (Figure 1, compounds 1-5). ${ }^{[8]} \mathrm{A}$ less conventional example of such dual coumarin-xanthene molecule was reported by Lin et al. who devised an unusual photocaging strategy for rosamine dyes (Figure 1, compounds 6 and 7). ${ }^{[9]}$ In this case, the coumarin-4-yl-methyl moiety is the photolabile protecting group and its (reversible) covalent conjugation to xanthene core is based on an unprecedented intramolecular carbon-carbon spirocyclization. In the light of the foregoing, we decided to explore novel directly linked coumarin-pyronin dual dyes with two aims in view: (1) to eventually disclose higher performances rosamine-like fluorophores and (2) to facilitate both the fine-tuning of spectral features of the xanthene core through structural modulations of meso-coumarin photoactive substituent, and the implementation of effective sensing mechanisms that may provide diverse signaling responses upon the action of stimuli. To the best of our knowledge, only one example of such structure was published in the literature (Figure 1, compound RD42), as one member of a diversity-oriented rhodamine/rosamine library of 69 compounds recently constructed by the Yang group to identify wide spectrum bactericidal agents with low inducible resistance against resistant pathogens. ${ }^{[10]}$ Their synthetic pathway was based on nucleophilic condensation of a dilithium reagent (formally derived from 4,4'-methylenebis( $N, N$-diethylaniline $)$ ) with the corresponding carboxylic acid derivative (e.g., ethyl 7(diethylamino)coumarin-3-carboxylate for the synthesis of RD42) The practical implementation of such reaction, especially the dual halogen-lithium exchange step, is arduous task and the use of a strongly basic and nucleophilic bis-aryllithium reagent may be problematic in terms of functional group tolerance preintroduced into the coumarin core. To overcome such limitations and to rapidly access a wide range of coumarin-xanthene hybrid dyes, there is a need to devise an alternative synthetic strategy that, ideally, would enable the direct covalent coupling of coumarin unit to xanthene scaffold (i.e., pyronin unit) under mild conditions. Since one of the main features of pyronin dyes is the reactivity of their unsubstituted meso-position (i.e., C-9 position) towards nucleophiles, ${ }^{[11]}$ we assumed that their reaction with coumarin-based cyclic $C$-nucleophiles may be a simple and effective way to achieve this goal (Figure 1).

Herein, we report our findings related to the discovery of two novel synthetic routes, that take advantage of the latent nucleophilic character of the C-3 position of 4-hydroxycoumarin derivatives ${ }^{[12]}$, leading to the preparation of a set of six coumarinpyronin hybrid structures which can be assumed as unusual rosamine dyes. We evaluated the spectral properties of these fluorophores either under simulated physiological conditions or in organic media. We have also performed Time-Dependent Density Functional Theory (TD-DFT) and Second-Order Coupled-Cluster [CC2] computations to get insights into their unusual electronic absorption and fluorescence emission properties and these suggest clearly a dark state quenching through a TICT like mechanism. Preliminary fixed-cell imaging experiments are presented as well so to assess cell permeability of these xanthene-based fluorescent markers.

\section{Results and Discussion}

\section{Synthesis of coumarin-pyronin hybrid dyes through formal Knoevenagel condensation reactions}

Depending on the size and steric hindrance of meso-aryl substituent of the targeted xanthene dye, several traditional and exotic synthetic methods are available in the literature. ${ }^{[13]} \mathrm{A}$ classification based on the electrophilic or nucleophilic character of the reagent typically used for formal C-9 functionalization of the xanthene core is generally admitted. ${ }^{[14]}$ Surprisingly, the known reactivity of pyronin dyes linked to the marked electrophilic character of their meso-position, has, to our knowledge, never been employed to introduce structural and functional diversity through addition of cyclic $C$-nucleophiles and subsequent spontaneous or oxidant-mediated re-aromatization. By analogy with an unprecedented reaction between unsymmetrical pyronin AR116 and edaravone (i.e., 1-phenyl-3methyl-5-pyrazolone, pKa 7.0 in water) occurring under simulated physiological conditions (i.e., phosphate buffer (PB), $\mathrm{pH}$ 7.5), recently highlighted by us, ${ }^{[15]}$ we thought that condensation reaction between a pyronin dye and 4hydroxycoumarin derivatives (their $\mathrm{C}-3$ position being a latent $C$ nucleophilic center) may provide a facile and direct entry to a novel class of rosamine-based fluorophores (Figure 1). This strategy was first implemented by mixing AR116 and 4,7dihydroxycoumarin in PB $(100 \mathrm{mM}, \mathrm{pH} 7.5)$ with co-solvents (PB/MeCN/DMSO, 2:1:1, v/v/v) at $60{ }^{\circ} \mathrm{C}$ for $24 \mathrm{~h}$ (Scheme 1, top). Despite a moderate conversion rate (ca. $30 \%$ ), the desired product 8 could be isolated though in a $6 \%$ yield because its mediocre solubility/polarity led to the loss of significant amounts of fluorophore during the semi-preparative RP-HPLC purification. To overcome the above problems, a further reaction was conducted with readily accessible and less polar pyronin B. This 
latter symmetrical xanthene dye was reacted with 4,7dihydroxycoumarin in DMF in the presence of triethylamine (TEA) at $50{ }^{\circ} \mathrm{C}$ for $22 \mathrm{~h}$ (Scheme 1, bottom). A sequential twostep purification protocol by flash-column chromatography over silica gel and preparative TLC provided the desired coumarinpyronin B hybrid dye 9. These first results clearly demonstrate that the direct condensation method is particularly suited to meso functionalization of symmetrical pyronin dyes with latent cyclic $C$-nucleophiles. The need to devise a more versatile synthetic route applicable to unsymmetrical pyronins led us to consider the use of a mixed bis-aryl ether bearing a reactive formyl group and acting as a xanthene precursor (known as "covalent-assembly" type probes) ${ }^{[16]}$. Indeed, the Yang group and some of us have shown that activation of aldehyde or deprotection of primary aniline of such "caged" pyronin precursors triggered a domino cyclization-aromatization reaction leading to in situ formation of fluorescent pyronin. ${ }^{[15,17]} \mathrm{A}$ related strategy that involves Knoevenagel condensation between the benzaldehyde derivative 10 (i.e., a mixed bis-aryl ether functionalized with a formyl group and readily accessible through a copper-catalyzed Ullmann cross-coupling reaction performed under conditions reported by Anzalone et al. ${ }^{[18]}$ ), followed by TFA-mediated deprotection of primary aniline, has therefore been implemented (Scheme 2). 4-Hydroxy derivatives of 7hydroxycoumarin (umbelliferone), 7- $\mathrm{N}, \mathrm{N}$-dimethylaminocoumarin (DMAC), 7-N,N-diethylaminocoumarin (DEAC) and coumarin $6 \mathrm{H}$ were selected as latent cyclic $C$-nucleophiles and the optimal reaction conditions were found to be: cat. piperidine, anhydrous $\mathrm{Na}_{2} \mathrm{SO}_{4}, \mathrm{EtOH}$, reflux, $3 \mathrm{~h}$ or $5 \mathrm{~h}$. Compound 11 and three additional coumarin-pyronin hybrid dyes 12-14 were obtained as TFA salts and readily purified by flash-column chromatography over silica gel (overall yield for the three steps in the range 3-7\% against $0.03 \%$ for the first strategy that takes account of the synthesis of pyronin AR116). The structures of these six novel rosamine dyes were unambiguously confirmed by ESI-LRMS and NMR spectroscopic analyses (see the Supporting Information). However, it is important to note that the recording of NMR spectra was complicated by the very slow relaxation of some aromatic proton and carbon signals, possibly due to ketoenol tautomerism occurring for 4-hydroxycoumarin moiety, in polar solvents such as $\mathrm{CD}_{3} \mathrm{OD}$ and $\left[\mathrm{D}_{6}\right] \mathrm{DMSO}$. In the case of $7-$ methoxy derivative 11 , a decent quality and interpretable ${ }^{1} \mathrm{H}$ NMR spectrum was only obtained after adding $10 \%$ of $\left[D_{1}\right]$ TFA in $\mathrm{CDCl}_{3}$. Conversely, it was impossible to obtain a good quality ${ }^{13} \mathrm{C}$ NMR spectrum despite of extended acquisition time on a $600 \mathrm{MHz}$ spectrometer. The purity of each compound (determined through RP-HPLC analyses) was found to be equal to or above $96 \%$, and thus being suitable for an accurate determination of their photophysical properties. The mass percentage of TFA in samples of 9 and 11-14 was determined by ion chromatography.

\section{Photophysical properties of coumarin-pyronin hybrid dyes}

The photophysical properties of these novel coumarin-pyronin hybrid dyes were evaluated in different media including $\mathrm{CHCl}_{3}$, PB (100 mM, pH 7.5) as simulated physiological conditions and also carbonate-bicarbonate buffer ( $\mathrm{CB}, 100 \mathrm{mM}, \mathrm{pH}$ 10.2) to assess the spectral consequences of the formation of the phenolate anion form in the ground state. These spectroscopic data are gathered in Table 1, and the corresponding electronic absorption, excitation, and emission spectra are available in the Supporting Information (see Figure 2 for selected spectra of rosamines 9 and 11). Irrespective of the solvent or the C-7 substituent of the 4-hydroxycoumarin unit, the UV-visible absorption spectra are almost the perfect sum of those expected for the coumarin and pyronin scaffolds as revealed by two distinct maxima in the UV-A/B and in the yellow-green portion of the visible spectrum respectively. Interestingly, the wavelength of maximum absorption assigned to xanthene chromophore is almost the same as that determined for the parent pyronin AR116 or pyronin B (comparison with entries 19-22, Table 1). Furthermore, the vibronic structure typical of cyanine dyes is imprinted into the shape of this visible absorption band. All these observations suggest that there are very limited interactions between the two chromophore moieties in the ground electronic state. Moreover, first principle calculations have confirmed the strong twist between the coumarin and pyronin units confirming that they can be regarded as two almost independent systems in the ground state (vide infra). Compared to parent pyronin dyes and more conventional rhodamine/rosamine derivatives, the most differentiating and somewhat disappointing spectral feature of these xanthene-based fluorophores is undoubtedly their poor emission efficiency in solution (relative fluorescence quantum yields within the range 1-13\% except for 9 and 11 in $\mathrm{CHCl}_{3}, 84 \%$ and $62 \%$ respectively). These experimental data and the associated theoretical calculations (vide infra) support the hypothesis that a dark state quenching mechanism is operative for these photoactive molecules. ${ }^{[19]}$ Indeed, an assumed intermingling between frontier molecular orbitals energy levels of the two chromophoric units (i.e., coumarin and pyronin) is likely to promote population to a dark state from which only nonradiative decay can occur. The substituent effect on fluorescence quantum yield of these coumarin-pyronin hybrids show a clear trend, especially in $\mathrm{CHCl}_{3}$ (Table 1, entries 1, 7, 10, 13 and 16). Indeed, as illustrated by the decreasing rank order listed below, the higher the electron-donating ability of C-7 substituent of coumarin, the lower the value of fluorescence efficiency of the corresponding hybrid: 11 (-OMe substituent, $\Phi_{F}$ $62 \%)>12\left(-\mathrm{NMe}_{2}\right.$ substituent, $\left.\Phi_{\mathrm{F}} 7 \%\right)>13\left(-\mathrm{NEt}_{2}\right.$ substituent, $\left.\Phi_{\mathrm{F}} 3 \%\right)>14$ (julolidine as tertiary aniline, $\left.\Phi_{\mathrm{F}} 4 \%\right)>8(-\mathrm{OH}$ substituent, $\left.\Phi_{\mathrm{F}}<1 \%\right)$. As seen below in the theoretical modelling section, this trend can be understood by the downshift of the CT transition between the coumarin and pyronin when the donating character of the group becomes stronger: for 11, such quenching CT transition is irrelevant, whereas for, e.g., 13 it is lowered enough to compete with the emissive state. A further comparative study between coumarin-pyronin hybrids $\mathbf{8}$ and $\mathbf{9}$ distinguished by the sole substitution pattern of their xanthene core (i.e., a single or two $-\mathrm{NEt}_{2}$ groups) is also in line with the previous explanation/hypothesis. Indeed, one notes the remarkable value of fluorescence quantum yield of $9\left(\Phi_{F} 84 \%\right.$ in $\mathrm{CHCl}_{3}$ ) compared to the lack of emissive properties for its analog 8 bearing unsymmetrical xanthene core. The ability to dramatically change the fluorescence properties of such 
coumarin-pyronin hybrid skeleton through rather simple structural modification, e.g., the alkylation of a primary aniline moiety, may be an attractive feature for practical applications in the field of reactivity-based molecular sensing, of this novel class of xanthene-based fluorophores.

In addition to measurements in organic media, we have also studied the spectral behavior of coumarin-pyronin hybrid dyes in aqueous buffers especially at $\mathrm{pH} 10.2$ (carbonate-bicarbonate buffer). The purpose being to assess the possible influence of the protonation state of enol moiety found in the coumarin fragment. For all compounds, only a very weak yellow-orange fluorescence emission intensity was observed, whatever the substitution pattern of coumarin and pyronin units. ${ }^{\text {[3ai] It }}$ prevented us to accurately determine relative fluorescence quantum yields, roughly estimated at less than $1 \%$. For hybrid dye 8 bearing an hydroxyl group as C-7 substituent of coumarin unit, a strong violet-blue fluorescence centered at $370 \mathrm{~nm}$ (upon UV-B excitation at $325 \mathrm{~nm}$ ) was observed (see the Supporting Information), confirming that only a weak electronic communication between the two chromophore units takes place in the ground state. The behavior of other phenol-based hybrid dye 9 is somewhat different because UV-B excitation produces two very weak fluorescence emission bands centered at $393 \mathrm{~nm}$ and $579 \mathrm{~nm}$ respectively. Under simulated physiological conditions (PB, $100 \mathrm{mM}, \mathrm{pH}$ 7.5), only this latter hybrid molecule synthesized from pyronin $B$, exhibited a significant fluorescence emission centered at $579 \mathrm{~nm}$ and characterized by a quantum yield of $13 \%$. Interestingly, the perfect matching between the absorption and excitation spectra allows us to discard the formation of non-emissive aggregates (i.e., H-type homodimers $)^{[20]}$ as the primary source for the modest fluorescence yield obtained in neutral aqueous medium (again see theory below for rationalization). During this campaign of spectral measurements, we have also highlighted an unexpected and interesting behavior of coumarin-pyronin hybrid dyes (TFA salt form) after either their prolonged storage (ca. 1 month) in solution in DMSO or a further drying of powders under vacuum. Indeed, the repeat recording of absorption spectra in $\mathrm{CHCl}_{3}$, shows clearly the formation of a novel species characterized by a blue-shifted (ca. $30 \mathrm{~nm}$ ) maximum absorption wavelength and the loss of emissive properties. The addition of $1 \%(\mathrm{v} / \mathrm{v})$ TFA in $\mathrm{CHCl}_{3}$ enables to restore the initial spectral features (see the Supporting Information for the selected absorption spectra of 9 and 11, Figures S13 and S14). One possible explanation for this, that will merit further investigation, may be linked to the formation of a non-emissive keto form (i.e., 4-oxocoumarin bearing a xanthen-9-ylidene moiety as C-3 substituent, Figure 3 ), favored by slow and gradual evaporation of TFA. To date, no publications have reported or demonstrated the existence and spectral properties of such unusual xanthene derivatives. However, pyronin B-related compounds bearing an easily enolizable compound as meso-substituent have been described by Shandura et al. (Figure 3, compounds 15 and $16)^{[21]}$. The fact that these molecules were found to be nonfluorescent in $\mathrm{MeCN}$, provides an additional argument for this hypothesis.

Finally, further experiments have enabled us to pinpoint an additional attractive spectral property for these photoactive systems, notably those that exhibit intense emission in $\mathrm{CHCl}_{3}$. When rosamine 9 was excited at $310 \mathrm{~nm}$ (excitation of the coumarin moiety), the emission intensity of at $580 \mathrm{~nm}$ was found to be larger than that of pyronin B alone (Figure 4). These results indicate that the energy of the coumarin moiety is successfully transferred to the pyronin unit. A large pseudoStokes shift of up to $270 \mathrm{~nm}\left(>15100 \mathrm{~cm}^{-1}\right)$ was thus achieved. A similar spectral behavior was obtained with pyronin-based hybrid 11 (pseudo-Stokes shift $=247 \mathrm{~nm}, 14300 \mathrm{~cm}^{-1}$, Figure S15) but this energy transfer process partly disappeared in carbonate-bicarbonate buffer ( $\mathrm{pH}$ 10.2) and a weak violet-blue fluorescence emission assigned to coumarin unit was also detected (see Figures S16-S18 for the corresponding emission curves of rosamines 8,9 and 11). In the light of both these experimental observations and previous interpretations about the photophysics of coumarin-pyronin hybrid dyes (vide supra), we assumed that these donor-acceptor systems act as dark through-bond energy transfer (DTBET) cassettes recently proposed by the Tang group. ${ }^{[22],[23]}$ The energy transfer efficiency (ETE) parameter was determined using the methodology published by Chen et al. ${ }^{[22]}$ and found to be equal to $62 \%$ for 9 and $100 \%$ for 11 (see Experimental Section for details about this calculation). It is worthwhile mentioning that the intrinsic fast non-radiative decay of the coumarin moiety prevents the observation of its emission even though the ETE in $\mathbf{9}$ is only $62 \%$. Interestingly, modulation of this photophysical mechanism through protection-deprotection of the hydroxyl group attached at C-7 position of coumarin unit may open the way to a nextgeneration of analyte-responsive ratiometric fluorescent probes. ${ }^{[7 a, 24]}$

\begin{tabular}{|c|c|c|c|c|c|c|}
\hline Dye $e^{[a]}$ & Solvent & $\begin{array}{l}\text { Abs max }{ }^{[\mathrm{b}]} \\
{[\mathrm{nm}]}\end{array}$ & $\begin{array}{c}E m \max \\
{[\mathrm{nm}]}\end{array}$ & $\begin{array}{c}\text { Stokes } \\
\text { shift } \\
{\left[\mathrm{cm}^{-1}\right]}\end{array}$ & $\begin{array}{c}\varepsilon \\
{\left[\mathrm{M}^{-1} \mathrm{~cm}^{-1}\right]}\end{array}$ & $\Phi_{F}^{[c]}$ \\
\hline \multirow{3}{*}{8} & $\mathrm{CHCl}_{3}$ & 510 & 559 & 1719 & 49000 & $<0.01$ \\
\hline & $\begin{array}{c}\mathrm{PB} \\
\mathrm{pH} 7.5\end{array}$ & 535 & -[d] & $-[d]$ & 58900 & -[d] \\
\hline & $\begin{array}{c}\mathrm{CB} \\
\mathrm{pH} 10.2\end{array}$ & 524 & $-[d]$ & _[d] & 52300 & $<0.01$ \\
\hline \multirow{3}{*}{9} & $\mathrm{CHCl}_{3}$ & 560 & 583 & 704 & 135800 & 0.84 \\
\hline & PB & 560 & 579 & 586 & 132500 & 0.13 \\
\hline & $\begin{array}{c}\mathrm{CB} \\
\mathrm{pH} 10.2\end{array}$ & 560 & $-^{[d]}$ & -d] & 135200 & $<0.01$ \\
\hline \multirow{3}{*}{11} & $\mathrm{CHCl}_{3}$ & 540 & 557 & 565 & 88200 & 0.62 \\
\hline & PB & 536 & -[d] & -[d] & 36800 & 0.015 \\
\hline & $\begin{array}{c}\mathrm{CB} \\
\mathrm{pH} 10.2\end{array}$ & 536 & _[d] & _[d] & 43800 & $<0.01$ \\
\hline \multirow{2}{*}{12} & $\mathrm{CHCl}_{3}$ & 540 & 556 & 533 & 95100 & 0.07 \\
\hline & PB & 535 & _[d] & - [d] & 100600 & $<0.01$ \\
\hline
\end{tabular}




\begin{tabular}{|c|c|c|c|c|c|c|}
\hline & $\begin{array}{c}\mathrm{CB} \\
\mathrm{pH} 10.2\end{array}$ & 535 & $-[d]$ & $-[d]$ & 92600 & $<0.01$ \\
\hline \multirow{3}{*}{13} & $\mathrm{CHCl}_{3}$ & 541 & 564 & 754 & 83700 & 0.03 \\
\hline & PB & 535 & ${ }_{-[d]}^{[d]}$ & [d] & 77100 & $<0.01$ \\
\hline & $\begin{array}{c}\mathrm{CB} \\
\mathrm{pH} 10.2\end{array}$ & 535 & -[d] & $-[d]$ & 77800 & $<0.01$ \\
\hline \multirow{3}{*}{14} & $\mathrm{CHCl}_{3}$ & 538 & 561 & 762 & 63800 & 0.04 \\
\hline & PB & 536 & -[d] & $-[d]$ & 63200 & $<0.01$ \\
\hline & $\begin{array}{c}\mathrm{CB} \\
\mathrm{pH} 10.2\end{array}$ & 535 & $-[d]$ & _d] & 63400 & $<0.01$ \\
\hline \multirow[b]{2}{*}{ AR116 } & $\mathrm{CHCl}_{3}$ & 536 & 545 & 308 & 99800 & 0.28 \\
\hline & $\begin{array}{c}\mathrm{PB} \\
\mathrm{pH} \\
7.5^{[\mathrm{e}]}\end{array}$ & 527 & 548 & 727 & 64800 & 0.07 \\
\hline \multirow[b]{2}{*}{ PY B } & $\mathrm{CHCl}_{3}$ & 558 & 569 & 356 & 92100 & 0.59 \\
\hline & $\begin{array}{c}\mathrm{H}_{2} \mathrm{O} \\
\mathrm{pH} 6.8^{[]]}\end{array}$ & 552 & 572 & 633 & - & 0.18 \\
\hline
\end{tabular}

broader, but more importantly, the emission quantum yield drops drastically to a trifling value whereas the fluorescence of AR116 remains non-negligible in the same aq. buffer (Table 1). We therefore envisaged the deprotonation of $\mathbf{1 1}$ to be responsible for this effect. Three tautomers can be drawn for a neutral (unprotonated) 11 (see right-hand side of Figure 5): a zwitterionic structure $(Z)$ a neutral canonical one $(N)$, and the corresponding tautomer $(T)$. In water, DFT calculations predict the former $Z$ isomer to be favored by 21.1 and $27.1 \mathrm{kcal}^{\mathrm{mol}}{ }^{-1}$ over $N$ and $T$, respectively, which follows chemical intuition of deprotonation of the $\mathrm{OH}$ group at position 4 of the coumarin. Interestingly, for $11(Z)$ form, our calculations provide two closelying excited-states in the visible domain, see Figure 6 . Although such data are obtained with CC2 corrections, it should be underlined that, on the one hand, the accuracy of the approach is typically in the 0.1-0.2 eV range, and, on the other hand, that some intensity borrowing between the two transitions might take place. Interestingly, the lowest transition shows a clear CT character from the anionic coumarin (mostly in blue in Figure 6) to the cationic pyronin (mostly in red) with $\mathrm{q}^{\mathrm{CT}}=0.90 \mathrm{e}$ and $\mathrm{d}^{\mathrm{CT}}=$ $2.23 \AA$, indicating a significant CT between the two moieties. In contrast the second transition of $11(Z)$ conserves the topology found in $11(C)$ in $\mathrm{CHCl}_{3}\left(\mathrm{q}^{\mathrm{CT}}=0.48 \mathrm{e}\right.$; $\mathrm{d}^{\mathrm{CT}}=1.25 \AA$ ). For the records, the presence of a low-lying $C T$ is found at $C$ C2 level, but also with $\mathrm{CIS}(\mathrm{D}), \mathrm{ADC}(2)$, as well as TD-M06-2X. When relaxing the geometries of these two excited states with TD-DFT, one obtains vastly different structures, as the lowest state yields to a TICT-like structure with perfectly orthogonal coumarin and pyronin moieties, corresponding to a dark and extremely lowlying state ( $f=0$ with a $\Delta \mathrm{E}$ of $1.3 \mathrm{eV}$ or $953 \mathrm{~nm}$, Figure 6), whereas the relaxation of the second state leads to a bright transition similar to the one found in 11(C). Obviously, emission from the relaxed $S_{1}$ is impossible due to both the zero oscillator strength (negligible coupling, hence very low radiative constant) and a transition energy significantly smaller than $1.5 \mathrm{eV}$, indicating very efficient non-radiative pathways. This explains the strong quenching obtained experimentally for 11, the residual emission with a very small $\Phi_{\mathrm{F}}$ likely coming from the $S_{2}$ state, that has conserved the emitting topology of the cationic form. On a more semantic note, given that theory predicts that almost one electron is transferred during this $S_{0}-S_{1}$ excitation, the former transition could also be seen as a PeT between the two moieties at the Frank-Condon point ${ }^{[19]}$, but the very low energy of the relaxed $S_{1}$ would likely make the state undetectable by experimental means due to too fast nonradiative deactivation. This general idea of the presence of competing excited states close in energy at the Frank-Condon point but of vastly different natures pertains in the other compounds as we exemplify below.

As regards the rosamine dye 13 , an equivalent to 11 equipped with a stronger electron-donating diethylamino group on the coumarin moiety, the major difference with respect to 11 is the very low quantum yield of emission in $\mathrm{CHCl}_{3}$ : $\Phi_{\mathrm{F}}=0.03$ for 13, only $5 \%$ of the corresponding value for 11 (Table 1). Given the above results, we have considered $13(C)$ to be the form present in $\mathrm{CHCl}_{3}$. Our theoretical protocol returns two very close lying vertical excitations on the $S_{0}$ geometry: a $S_{0}-S_{1}$ at $2.11 \mathrm{eV}$ and a $S_{0}-S_{2}$ transition at $2.15 \mathrm{eV}$ (Figure 7). Such difference is of 
course within theory's error bar but one can trust the existence of two very close transitions. The lowest transitions present a clear CT character from the donating coumarin to the accepting pyronin an effect possible due to the strong donating character of the diethylamino group of the coumarin, whereas the second transition has a topology similar to the one found in 11(C). Optimization of the geometry of the $S_{1}$ does not significantly change the inter-ring dihedral that only goes from $62^{\circ}$ to $65^{\circ}$, but again yields a very low-lying "fluorescence" wavelength of 810 $\mathrm{nm}$ (ca. $1.5 \mathrm{eV}$ ), indicating no emission (see Figure S19 in the Supporting Information). This explains, the strong drop of $\Phi_{F}$ in going from 11 to 13 in $\mathrm{CHCl}_{3}$. Intuitively, the stronger the electron-donating character of the C-7 substituent of the coumarin, the lower the $S_{0}-S_{1}$ excited state, and hence, the stronger the quenching, which first experimental trends (vide supra). In PB ( $\mathrm{pH} 7.5)$, the same behavior as described above for $11(Z)$ is found, with a low-lying dark state and a residual emission should come from the $S_{0}-S_{2}$ transition (see Figure $S 19$ in the Supporting Information).

For 9 , the striking experimental feature is the conservation of a non-negligible $\Phi_{\mathrm{F}}$ at $\mathrm{pH} 7.5(0.13$, the largest of the series), whereas, as in 11, the fluorescence is very bright in $\mathrm{CHCl}_{3}$ (Table 1). In the latter environment, only one structure can be drawn and it mostly conserves the features of 11(C) with a bright low-lying transition, localized in the pyronin core, and a minimal geometric reorganization in the excited-state. In PB ( $\mathrm{pH} 7.5)$, three tautomers can be envisaged (see Figure $\mathrm{S} 20$ in the Supporting Information), but the deprotonation takes place at the $4-\mathrm{OH}$ position as expected, yielding a structure similar to $11(Z)$. The main change between $9(Z)$ and $11(Z)$ is however the ordering of the excited states. In the former compound, our best estimate is that the CT state is actually lying higher than the standard bright cyanine-like transition due to the stronger electron-donating character of the $\mathrm{NEt}_{2}$ group added to the pyronin, see Figure 8 . This allows for a non-trifling emission from $9(Z)$.

As can be seen by these three detailed examples, it seems therefore that the relative emission quantum yields observed for the different rosamine dyes in different media are mainly guided by the relative energies of a bright emissive state localized on the pyronin, and a dark coumarin-to-pyronin CT state that quenches the emission through the formation of a (nearly) dark low-lying TICT.

\section{Fluorescence imaging in fixed cells with coumarin-pyronin hybrid dyes 9 and 11}

To glean some preliminary insights into the possible use of such xanthene-type hybrid dyes in biological systems, we conducted fluorescence fixed-cell imaging experiments. We selected compounds 9 and 11 because they have the highest values of fluorescence brightness in simulated physiological conditions (17 $225 \mathrm{M}^{-1} \mathrm{~cm}^{-1}$ and $550 \mathrm{M}^{-1} \mathrm{~cm}^{-1}$ respectively). They were incubated in A549 cells ( $5 \mu \mathrm{M})$ for $2 \mathrm{~h}$. The cells were then fixed using a $4 \%$ paraformaldehyde solution in phosphate-buffered saline (PBS) and studied by confocal laser scanning microscopy. The results shown in Figure 8 suggest cellular penetration though passive way of the two fluorophores thereby confirming their viability for use in fluorescence imaging. No particular localization was noted during these preliminary experiments showing obvious stains in the cytoplasm (and not in the nucleus). The cytoplasmic staining seems more homogeneous in the case of rosamine 9 while intermittent labeling and partial intracellular precipitation are observed in the case of rosamine 11. This behavior can be related to results arising from in vitro spectral measurements conducted in simulated physiological conditions (PB, pH 7.5, Table 1) and clearly highlighting the superior spectral performances of rosamine $\mathbf{9}$ in biological media.

\section{Conclusions}

In summary, we successfully synthesized six novel rosamine dyes based on an unprecedented 4-hydroxycoumarin-pyronin hybrid skeleton, by facile and straightforward methods. Photophysical characterizations and first-principle calculations demonstrated that the coumarin unit, in most cases, negatively affects the fluorescence properties of pyronin fragment within the yellow-orange spectral range, especially in aqueous media. In contrast, the two most fluorescent coumarin-pyronin hybrid dyes 9 and 11 have been identified as effective dark TBET cassettes and can thus be regarded as attractive candidates for the development of small-molecule-based ratiometric fluorescent probes for chemo/biosensing and bioimaging of various analytes of interest (e.g., disease-associated biomarkers, ...). ${ }^{[2,7 \mathrm{7a}, 24,27]} \mathrm{A}$ further argument for further practical application of these unusual rosamine dyes in biological systems was also provided by preliminary cell-imaging studies showing the cell permeability of these xanthene-based fluorophores.

\section{Experimental Section}

\section{General}

Unless otherwise noted, all commercially available reagents and solvents were used without further purification. TLC was carried out on Merck Millipore DC Kieselgel 60 F-254 aluminum sheets. The spots were directly visualized or through illumination with a UV lamp $(\lambda=254 / 365$ $\mathrm{nm})$. Preparative TLC purifications were performed on Merck Millipore PLC Kieselgel $60 \mathrm{~F}-254$ glass plates $(2 \mathrm{~mm}, 20 \times 20 \mathrm{~cm}$ ). Purifications by flash-column chromatography were performed on silica gel $(40-63 \mu \mathrm{m})$ from VWR. Anhydrous DMSO and DMF was purchased from Carlo Erba, and stored over $3 \AA$ molecular sieves. Piperidine (peptide grade, SOL010) and TFA (peptide grade, SOL-011) were provided by Iris Biotech $\mathrm{GmbH}$. Formic acid (FA, puriss p.a., ACS reagent, reag. Ph. Eur., $\geq 98 \%$ ), 4,7-dihydroxycoumarin (97\%) and DMSO (molecular biology grade) were provided by Merck Millipore (Sigma-Aldrich brand). 4-Hydroxy-7methoxycoumarin $(98 \%)$ was purchased from TCl Europe N.V. Chloroform $\left(\mathrm{CHCl}_{3}\right.$, for spectroscopy, \#167730010) was purchased from Acros Organics, The HPLC-gradient grade acetonitrile (MeCN) was obtained from Carlo Erba or Fisher Chemical. All aqueous buffers used in this work and aqueous mobile-phases for HPLC were prepared using water purified with a PURELAB Ultra system from ELGA (purified to 18.2 $\mathrm{M} \Omega . \mathrm{cm}$ ). 4-(Diethylamino)salicylaldehyde was recrystallized in deionized water and dried by lyophilization, prior to use. Unsymmetrical pyronin AR116 (TFA salt) [2101186-12-1], pyronin B (HBr salt) [1229438-44-1], $\mathrm{N}$-Boc-3-iodoaniline [143390-49-2], and the $4-\mathrm{OH}$ derivatives of 7(dimethylamino)coumarin [64369-54-6], 7-(diethylamino)coumarin [64369-55-7] and coumarin $6 \mathrm{H}$ (trade name for this julolidine-based coumarin) [213481-01-7] were prepared according to literature procedures. ${ }^{[11,15,28]}$ 


\section{Instruments and methods}

Freeze-drying operations were performed with a Christ Alpha 2-4 LD plus Centrifugation steps were performed with a Thermo Scientific Espresso Personal Microcentrifuge instrument. ${ }^{1} \mathrm{H}-,{ }^{13} \mathrm{C}$ - and ${ }^{19} \mathrm{~F}-\mathrm{NMR}$ spectra were recorded either on a Bruker Avance III $500 \mathrm{MHz}$ or on a Bruker Avance III HD $600 \mathrm{MHz}$ spectrometer (equipped with double resonance broad band probes). Chemical shifts are expressed in parts per million (ppm) from the residual non-deuterated solvent signal. ${ }^{[29]} J$ values are expressed in $\mathrm{Hz}$. IR spectra were recorded with a Bruker Alpha FT-IR spectrometer equipped with a universal ATR sampling accessory. The bond vibration frequencies are expressed in reciprocal centimeters $\left(\mathrm{cm}^{-1}\right)$ HPLC-MS analyses were performed on a Thermo-Dionex Ultimate 3000 instrument (pump + autosampler at $20{ }^{\circ} \mathrm{C}+$ column oven at $25{ }^{\circ} \mathrm{C}$ ) equipped with a diode array detector (Thermo-Dionex DAD 3000-RS) and MSQ Plus single quadrupole mass spectrometer. Purifications by semi-preparative HPLC were performed on a Thermo-Dionex Ultimate 3000 instrument (semi-preparative pump HPG-3200BX) equipped with an RS Variable Detector (VWD-3400RS, four distinct wavelengths within the range 190-800 $\mathrm{nm}$ ). Ion chromatography analyses (for the determination of TFA mass content in samples) were performed using a Thermo Scientific Dionex ICS 5000 ion chromatograph equipped with a conductivity detector CD (Thermo Scientific Dionex) and a conductivity suppressor ASRS-ultra II $4 \mathrm{~mm}$ (Thermo Scientific Dionex), and according to a method developed by the PACSMUB staff.[30] Lowresolution mass spectra (LRMS) were recorded on a Thermo Scientific MSQ Plus single quadrupole equipped with an electrospray (ESI) source (LC-MS coupling). UV-visible spectra were obtained either on a Varian Cary 50 Scan or on a Agilent Cary 60 (single-beam) spectrophotometer (software Cary WinUV) by using a rectangular quartz cell (Hellma, 100QS, $45 \times 12.5 \times 12.5 \mathrm{~mm}$, pathlength: $10 \mathrm{~mm}$, chamber volume: $3.5 \mathrm{~mL}$ ), at $25{ }^{\circ} \mathrm{C}$ (using a temperature control system combined with water circulation). The absorption spectra of coumarin-pyronin hybrid dyes were recorded in the corresponding solvent within the concentration range $3-20 \mu \mathrm{M}$ (three distinct dilutions for the accurate determination of molar extinction coefficients). The vast majority of fluorescence spectra were recorded on an HORIBA Jobin Yvon Fluorolog spectrofluorometer (software FluorEssence) at $25{ }^{\circ} \mathrm{C}$ (using a temperature control system combined with water circulation), with a standard fluorometer cell (Labbox, LB Q, light path: $10 \mathrm{~mm}$, width: $10 \mathrm{~mm}$, chamber volume: 3.5 $\mathrm{mL}$ ). The following set of parameters was used: shutter: Auto Open, excitation/emission slit $=5$ or $10 \mathrm{~nm}$, integration time $=0.1 \mathrm{~s}, 1 \mathrm{~nm}$ step $\mathrm{HV}(\mathrm{S} 1)=950 \mathrm{~V}$. All fluorescence spectra were corrected. Relative fluorescence quantum yields were measured in the corresponding buffer at $25^{\circ} \mathrm{C}$ by a relative method using the suitable standard (rhodamine 101 (Rho101): $\Phi_{\mathrm{F}}=100 \%$ in $\mathrm{MeOH}$, excitation at $520 \mathrm{~nm}$; dilution by a facto $\times 30$ between absorption and fluorescence measurements). The following equation was used to determine the relative fluorescence quantum yield:

$$
\Phi_{\mathrm{F}}(\mathrm{x})=\left(\mathrm{A}_{\mathrm{S}} / \mathrm{Ax}_{\mathrm{X}}\right)\left(\mathrm{F}_{\mathrm{X}} / \mathrm{F}_{\mathrm{S}}\right)\left(\mathrm{n}_{\mathrm{X}} / \mathrm{n}_{\mathrm{S}}\right)^{2} \Phi_{\mathrm{F}}(\mathrm{s})
$$

where $A$ is the absorbance (in the range of 0.01-0.1 A.U.), $F$ is the area under the emission curve, $\mathrm{n}$ is the refractive index of the solvents (at $25{ }^{\circ} \mathrm{C}$ ) used in measurements, and the subscripts $s$ and $x$ represent standard and unknown, respectively. The following refractive indices were used: 1.337 for $\mathrm{PB}, 1.333$ for carbonate-bicarbonate buffer (CB) 1.328 for $\mathrm{MeOH}$ and 1.446 for $\mathrm{CHCl}_{3}$. Some UV-visible and fluorescence spectra (especially the characterization of dark TBET mechanism through UV excitation) were also recorded on a SAFAS FIx-Xenius XC spectrofluorimeter using quartz cells (SAFAS, Quartz Suprasil for SAFAS flx Xenius, $45 \times 12.5 \times 12.5 \mathrm{~mm}$, pathlength: $10 \mathrm{~mm}$, chamber volume: $3.5 \mathrm{~mL}$ ), at $25{ }^{\circ} \mathrm{C}$ (using a temperature control system combined with water circulation). The following set of parameters was used: Ex/Em bandwidth $=5 \mathrm{~nm}$, integration time $=0.1 \mathrm{~s}, 1 \mathrm{~nm}$ step and tunable PMT voltage. All fluorescence spectra were corrected.

\section{High-performance liquid chromatography separations}

Several chromatographic systems were used for the analytical experiments (HPLC-MS) and the purification steps: System A: RP-HPLCMS (Phenomenex Kinetex $\mathrm{C}_{18}$ column, $2.6 \mu \mathrm{m}, 2.1 \times 50 \mathrm{~mm}$ ) with $\mathrm{MeCN}$ $(+0.1 \% \mathrm{FA})$ and $0.1 \%$ aqueous formic acid (aqueous $\mathrm{FA}, \mathrm{pH} 2.5)$ as eluents [ $5 \% \mathrm{MeCN}$ (0.1 $\mathrm{min}$ ) followed by linear gradient from $5 \%$ to $100 \%$ (5 min) of MeCN] at a flow rate of $0.5 \mathrm{~mL} / \mathrm{min}$. UV-visible detection was achieved at 220,260, 450 and $500 \mathrm{~nm}$ (+diode array detection in the range of $220-700 \mathrm{~nm}$ ). Low resolution ESI-MS detection in the positive/negative mode (full scan, 100-1000 a.m.u., data type: centroid, needle voltage: $3.0 \mathrm{kV}$, probe temperature: $350{ }^{\circ} \mathrm{C}$, cone voltage: $75 \mathrm{~V}$ and scan time: $1 \mathrm{~s}$ ). System B: semipreparative RP-HPLC (SiliCycle SiliaChrom $\mathrm{C}_{18}$ column, $10 \mu \mathrm{m}, 20 \times 250 \mathrm{~mm}$ ) with $\mathrm{MeCN}$ and TFA $0.1 \%$ as eluents [ $10 \% \mathrm{MeCN}$ (5 min), followed by a gradient of $10 \%$ to $20 \%$ MeCN (10 min), then $20 \%$ to $100 \% \mathrm{MeCN}$ (95 min)] at a flow rate of 20.0 $\mathrm{mL} / \mathrm{min}$. Quadruple UV-visible detection was achieved at 220, 260, 310 and $530 \mathrm{~nm}$.

\section{Syntheses}

\section{Synthesis of coumarin-pyronin hybrid dyes 8 (single-step pathway} from pyronin AR116)

The unsymmetrical pyronin AR116 (TFA salt, $16 \mathrm{mg}, 60 \mu \mathrm{mol}, 1$ equiv.) and 4,7-dihydroxycoumarin (21.4 $\mathrm{mg}, 0.12 \mathrm{mmol}, 2$ equiv.) were mixed together and solubilized in a mixture of PB/DMSO/MeCN $(2: 1: 1, \mathrm{v} / \mathrm{v} / \mathrm{v}$, $1.6 \mathrm{~mL})$, in a glass tube. This tube was sealed and the resulting reaction mixture was stirred at $60{ }^{\circ} \mathrm{C}$ for $24 \mathrm{~h}$. The reaction was checked for completion by RP-HPLC (system A). Then, the mixture was diluted with a $3: 7(\mathrm{v} / \mathrm{v})$ mixture of $0.1 \%$ aq. TFA and DMSO and purified by semipreparative RP-HPLC (system B, 5 injections, $t_{\mathrm{R}}=37.0-39.0 \mathrm{~min}$ ). The product containing fractions were lyophilized to give the coumarinpyronin hybrid dye 8 as dark purple amorphous powder $(2.3 \mathrm{mg}, 50 \mu \mathrm{mol}$, yield $6 \%$ )

\section{Synthesis of coumarin-pyronin fused dye 9}

Pyronin B ( $\mathrm{HBr}$ salt, $50 \mathrm{mg}, 0.104 \mathrm{mmol}, 1$ equiv.) and 4,7dihydroxycoumarin ( $23 \mathrm{mg}, 0.13 \mathrm{mmol}, 1,25$ equiv.) were mixed together and dissolved in dry DMF $(1 \mathrm{~mL})$ under argon atmosphere. TEA $(37 \mu \mathrm{L}$, $0.26 \mathrm{mmol}, 2.5$ equiv.) was then added and the resulting reaction mixture was stirred at $50{ }^{\circ} \mathrm{C}$ for $22 \mathrm{~h}$. The reaction was checked for completion by RP-HPLC (system A). The crude mixture was evaporated under reduced pressure and purified by flash-column chromatography on silica gel (eluent: a step gradient of $\mathrm{MeOH}$ in $\mathrm{DCM}$ from $0 \%$ to $5 \%$ ). The desired coumarin-pyronin hybrid dye $\mathbf{9}$ was recovered as a not perfectly pure compound and was subjected to a second chromatographic purification by preparative TLC (eluent: $\mathrm{DCM} / \mathrm{MeOH}$ 9:1, v/v). Pure sample of $\mathbf{9}$ was obtained as a dark purple amorphous powder (18 mg, $31 \mu \mathrm{mol}$, yield 30\%). $\mathrm{R}_{\mathrm{f}}(\mathrm{DCM} / \mathrm{MeOH}$ 9:1, $\mathrm{v} / \mathrm{v}): 0.8$; IR (ATR): $v=2967,1656,1639,1582,1525,1483,1434$ $1404,1330,1293,1270,1241,1196,1176,1158,1130,1107$, 1076, 1045, 1010, 977, 960, 940, 912, 845, 812, 773, 738, 702, 691, 681, 656, 639; ${ }^{1} \mathrm{H}$ NMR $\left(500 \mathrm{MHz}, \mathrm{CD}_{3} \mathrm{OD}\right): \delta=7.87\left(\mathrm{~d},{ }^{3} \mathrm{~J}_{\mathrm{H}, \mathrm{H}}=\right.$ $8.6 \mathrm{~Hz}, 1 \mathrm{H}), 7.76\left(\mathrm{~d},{ }^{3} \mathrm{~J}_{\mathrm{H}, \mathrm{H}}=9.5 \mathrm{~Hz}, 2 \mathrm{H}\right), 7.06\left(\mathrm{dd},{ }^{3} \mathrm{~J}_{\mathrm{H}, \mathrm{H}}=9.5,{ }^{4} \mathrm{~J}_{\mathrm{H}, \mathrm{H}}=2.5\right.$ $\mathrm{Hz}, 2 \mathrm{H}), 6.90\left(\mathrm{~d},{ }^{4} J_{\mathrm{H}, \mathrm{H}}=2.4 \mathrm{~Hz}, 2 \mathrm{H}\right), 6.79\left(\mathrm{dd},{ }^{3} J_{\mathrm{H}, \mathrm{H}}=8.6,{ }^{4} \mathrm{~J}_{\mathrm{H}, \mathrm{H}}=2.4 \mathrm{~Hz}\right.$, $1 \mathrm{H}), 6.74\left(\mathrm{~d},{ }^{4} \mathrm{~J}_{\mathrm{H}, \mathrm{H}}=2.3 \mathrm{~Hz}, 1 \mathrm{H}\right), 3.68\left(\mathrm{~d},{ }^{3} \mathrm{~J}_{\mathrm{H}, \mathrm{H}}=7.2 \mathrm{~Hz}, 8 \mathrm{H}\right), 1.32\left(\mathrm{t},{ }^{3} \mathrm{~J}_{\mathrm{H}, \mathrm{H}}\right.$ $=7.1 \mathrm{~Hz}, 12 \mathrm{H}) ;{ }^{13} \mathrm{C}$ NMR (151 MHz, [D 6 DMSO): $\delta=173.1,162.0,160.5$, $160.4,157.20,155.6,154.5,133.4,126.6,114.8,114.0,112.7,11.0$, 101.4, 94.9, 90.4, 30.7, 12.5; HPLC (system A): $t_{\mathrm{R}}=4.3 \mathrm{~min}$ (purity $>99 \%$ at $260 \mathrm{~nm}, 99 \%$ at $450 \mathrm{~nm}$ and $>99 \%$ at $500 \mathrm{~nm}$ ); LRMS (ESI+, recorded during RP-HPLC analysis): $m / z 499.2[\mathrm{M}]^{+}$(100), calcd for $\mathrm{C}_{30} \mathrm{H}_{31} \mathrm{~N}_{2} \mathrm{O}_{5}{ }^{+}$ 499.2; LRMS (ESI-, recorded during RP-HPLC analysis): $m / z 497.0\left[\mathrm{M}^{+}\right.$$2 \mathrm{H}^{-}(100)$, calcd for $\mathrm{C}_{30} \mathrm{H}_{29} \mathrm{~N}_{2} \mathrm{O}_{5}^{-} 497.2$.

\section{General procedure for synthesis of coumarin-pyronin hybrid dyes 8 and 11-14 (three-step pathway from 4- (diethylamino)salicylaldehyde)}

A mixture of 4-(diethylamino)salicylaldehyde (568 mg, $2.94 \mathrm{mmol}, 1.7$ equiv.), $\mathrm{N}$-Boc-3-iodoaniline (552 $\mathrm{mg}, 1.73 \mathrm{mmol}, 1$ equiv.), finely ground $\mathrm{K}_{3} \mathrm{PO}_{4}$ (732 mg, $3.45 \mathrm{mmol}, 2$ equiv.), Cul (33 mg, $0.17 \mathrm{mmol}, 0.1$ equiv.) and picolinic acid (43 mg, $0.35 \mathrm{mmol}, 0.2$ equiv.) in dry DMSO (4.2 mL) was heated in a sealed tube at $90{ }^{\circ} \mathrm{C}$ overnight. The reaction was checked for completion by TLC (eluent: DCM 100\%) and diluted with EtOAc. Thereafter, the resulting mixture was washed with deionized $\mathrm{H}_{2} \mathrm{O}$ thrice and with brine, dried over anhydrous $\mathrm{Na}_{2} \mathrm{SO}_{4}$, filtered and concentrated under reduced pressure. The resulting residue was purified by flash-column chromatography over silica gel (a step gradient of EtOAc in heptane from $10 \%$ to $20 \%$ ) to give $156 \mathrm{mg}$ of impure bis-aryl ether 10 (raw material yield 23\%). Not perfectly pure bis-aryl ether 10 
(156 mg, $0.41 \mathrm{mmol}, 1$ equiv.) was directly dissolved in absolute $\mathrm{EtOH}$ $(13 \mathrm{~mL})$ and the corresponding 4-hydroxycoumarin derivative $(0.43$ mmol, 1.05 equiv.), anhydrous $\mathrm{Na}_{2} \mathrm{SO}_{4}(30 \mathrm{mg})$ and piperidine (2 drops) were added. The resulting reaction mixture was stirred under reflux for 5 $\mathrm{h}$ (only $3 \mathrm{~h}$ for the synthesis of intermediate leading to rosamine 8). After completion (checked by TLC, eluent: DCM/MeOH 9:1, v/v), the mixture was concentrated under reduced pressure. The resulting residue was purified by flash-column chromatography over silica gel (step gradient of $\mathrm{MeOH}$ in DCM) to provide the not perfectly pure N-Boc coumarinpyronin hybrid dye. This latter compound was directly dissolved in DCM $(2 \mathrm{~mL})$ and TFA (1 mL) was added. The mixture was stirred at $0{ }^{\circ} \mathrm{C}$ for 15 $\mathrm{min}$, then at RT for $45 \mathrm{~min}$, and finally evaporated under reduced pressure. The crude product was purified by flash-column chromatography (step gradient of $\mathrm{MeOH}$ in DCM) to give the corresponding coumarin-pyronin hybrid as a dark red amorphous powder.

\section{Coumarin-pyronin hybrid dye 8}

4,7-Dihydroxycoumarin (76 mg) was used as the latent $C$-nucleophile. $N$ Boc intermediate was purified using the following eluent (a step gradient of $\mathrm{MeOH}$ in $\mathrm{DCM}$ from $0 \%$ to $10 \%$ ). The final coumarin-pyronin hybrid dye was purified using the following eluent (a step gradient of $\mathrm{MeOH}$ in DCM from $0 \%$ to $7 \%$ ) and recovered in a pure form $(45 \mathrm{mg}, 91 \mu \mathrm{mol}$ yield $5 \%$ over three steps, based on TFA mass $=8.8 \%$ determined by ionic chromatography). $\mathrm{R}_{\mathrm{f}}(\mathrm{DCM} / \mathrm{MeOH}$ 9:1, v/v): 0.7; IR (ATR): $v=$ $3328,3179,2959,2927,1665,1587,1544,1463,1434,1407$, 1381, 1329, 1268, 1241, 1176, 1125, 1072, 987, 942, 907, 820, 800, 771, 723, 705, 637; ${ }^{1} \mathrm{H}$ NMR (500 MHz, [D 6 DMSO): $\delta=10.21$ (s $1 \mathrm{H}), 7.81-7.58(\mathrm{~m}, 5 \mathrm{H}), 7.02\left(\mathrm{dd},{ }^{3} \mathrm{~J}_{\mathrm{H}, \mathrm{H}}=9.6 \mathrm{~Hz},{ }^{4} J_{\mathrm{H}, \mathrm{H}}=2.5 \mathrm{~Hz}, 1 \mathrm{H}\right)$ $6.87\left(\mathrm{~d},{ }^{4} \mathrm{~J}_{\mathrm{H}, \mathrm{H}}=2.5 \mathrm{~Hz}, 1 \mathrm{H}\right), 6.80\left(\mathrm{dd},{ }^{3} \mathrm{~J}_{\mathrm{H}, \mathrm{H}}=9.1 \mathrm{~Hz},{ }^{4} \mathrm{~J}_{\mathrm{H}, \mathrm{H}}=2.2 \mathrm{~Hz}, 1 \mathrm{H}\right)$, $6.72-6.65(\mathrm{~m}, 2 \mathrm{H}), 6.60\left(\mathrm{~d},{ }^{4} \mathrm{~J}_{\mathrm{H}, \mathrm{H}}=2.3 \mathrm{~Hz}, 1 \mathrm{H}\right), 3.61\left(\mathrm{q},{ }^{3} \mathrm{~J}_{\mathrm{H}, \mathrm{H}}=7.1 \mathrm{~Hz}, 4\right.$ $\mathrm{H}), 1.20\left(\mathrm{t},{ }^{3} \mathrm{~J}_{\mathrm{H}, \mathrm{H}}=7.0 \mathrm{~Hz}, 6 \mathrm{H}\right) ;{ }^{13} \mathrm{C}$ NMR $\left(126 \mathrm{MHz},\left[\mathrm{D}_{6}\right] \mathrm{DMSO}\right): \delta=$ $161.7,160.9,158.8,157.6,157.2,155.6,154.6,133.5,133.0,131.7$ $131.5,129.5,128.6,126.3,115.5,114.4,113.9,113.0,111.3,101.52$ $96.2,95.2,90.8,45.0,12.5 ;{ }^{19} \mathrm{~F} \mathrm{NMR}(565 \mathrm{MHz}$, [D6]DMSO): $\delta=-73.5(\mathrm{~s}$ $3 \mathrm{~F}, \mathrm{CF}_{3}-\mathrm{TFA}$ ). HPLC (system A): $t_{\mathrm{R}}=3.7$ min (purity $97 \%$ at $260 \mathrm{~nm}$, $99 \%$ at $450 \mathrm{~nm}$ and $97 \%$ at $500 \mathrm{~nm}$ ); LRMS (ESI+, recorded during RPHPLC analysis): $m / z 443.2\left[\mathrm{M}+\mathrm{H}^{+}(100)\right.$ and $885.2[2 \mathrm{M}+\mathrm{H}]^{+}(8)$, calcd for $\mathrm{C}_{26} \mathrm{H}_{23} \mathrm{~N}_{2} \mathrm{O}_{5}{ }^{+}$443.2; LRMS (ESI-, recorded during RP-HPLC analysis): $\mathrm{m} / \mathrm{z} 441.1 \mathrm{HM}^{-\mathrm{H}]^{-}}(100)$ and $883.2\left[2 \mathrm{M}-\mathrm{H}^{-}(10)\right.$, calcd for $\mathrm{C}_{26} \mathrm{H}_{21} \mathrm{~N}_{2} \mathrm{O}_{5}-441.2$

\section{Coumarin-pyronin hybrid dye 11}

4-Hydroxy-7-methoxycoumarin (82 $\mathrm{mg}$ ) was used as latent $C$-nucleophile. $\mathrm{N}$-Boc intermediate was purified using the following eluent (a step gradient of $\mathrm{MeOH}$ in $\mathrm{DCM}$ from $0 \%$ to $3 \%$ ). The final coumarinpyronin hybrid dye was purified using the following eluent (a step gradient of $\mathrm{MeOH}$ in $\mathrm{DCM}$ from $0 \%$ to $7 \%$ ) and recovered in a pure form $(31 \mathrm{mg}, 63 \mu \mathrm{mol}$, yield $4 \%$ over three steps, based on TFA mass = $5.8 \%$ determined by ionic chromatography). $\mathrm{R}_{\mathrm{f}}(\mathrm{DCM} / \mathrm{MeOH} 9: 1, \mathrm{v} / \mathrm{v})$ 0.7 ; IR (ATR): $v=3387,3308,3140,2973,2931,1669,1635,1591$ $1531,1494,1460,1433,1398,1334,1271,1234,1179,1154$, $1126,1100,1037,1013,975,935,904,824,800,773,739,720$ 708, 683,670,632; ${ }^{1} \mathrm{H}$ NMR $\left(500 \mathrm{MHz}, \mathrm{CDCl}_{3}+10 \%\left[\mathrm{D}_{1}\right] \mathrm{TFA}\right): \delta=$ $8.01\left(\mathrm{~d},{ }^{3} J_{\mathrm{H}, \mathrm{H}}=8.9 \mathrm{~Hz}, 1 \mathrm{H}\right), 7.58\left(\mathrm{~d},{ }^{3} \mathrm{~J}_{\mathrm{H}, \mathrm{H}}=9.6 \mathrm{~Hz}, 1 \mathrm{H}\right), 7.52\left(\mathrm{~d},{ }^{3} J_{\mathrm{H}, \mathrm{H}}=\right.$ $9.5 \mathrm{~Hz}, 1 \mathrm{H}), 7.04-6.99(\mathrm{~m}, 1 \mathrm{H}), 6.92\left(\mathrm{dd},{ }^{3} \mathrm{~J}_{\mathrm{H}, \mathrm{H}}=10.1,{ }^{4} J_{\mathrm{H}, \mathrm{H}}=2.4 \mathrm{~Hz}, 2 \mathrm{H}\right)$ $6.75\left(\mathrm{~d},{ }^{4} \mathrm{~J}_{\mathrm{H}, \mathrm{H}}=2.5 \mathrm{~Hz}, 3 \mathrm{H}\right), 3.95(\mathrm{~s}, 3 \mathrm{H}), 3.61\left(\mathrm{q},{ }^{3} J_{\mathrm{H}, \mathrm{H}}=7.2 \mathrm{~Hz}, 4 \mathrm{H}\right)$, $1.33\left(\mathrm{t},{ }^{3} \mathrm{~J}_{\mathrm{H}, \mathrm{H}}=7.2 \mathrm{~Hz}, 6 \mathrm{H}\right) ;{ }^{19} \mathrm{~F}$ NMR $\left(565 \mathrm{MHz},\left[\mathrm{D}_{6}\right] \mathrm{DMSO}\right): \delta=-73.6(\mathrm{~s}$ $3 \mathrm{~F}, \mathrm{CF}_{3}$-TFA); HPLC (system A): $t_{\mathrm{R}}=4.0 \mathrm{~min}$ (purity $99 \%$ at $260 \mathrm{~nm}$, $>99 \%$ at $450 \mathrm{~nm}$ and $>99 \%$ at $500 \mathrm{~nm}$ ); LRMS (ESI+, recorded during RP-HPLC analysis): $m / z 457.2[\mathrm{M}+\mathrm{H}]^{+}(100)$ and $913.3[2 \mathrm{M}+\mathrm{H}]^{+}(15)$ calcd for $\mathrm{C}_{27} \mathrm{H}_{25} \mathrm{~N}_{2} \mathrm{O}_{5}{ }^{+}$457.2; LRMS (ESI-, recorded during RP-HPLC analysis): $\mathrm{m} / \mathrm{z} 455.3\left[\mathrm{M}-\mathrm{H}^{-}(100)\right.$ and $911.2\left[2 \mathrm{M}-\mathrm{H}^{-}(22)\right.$, calcd for $\mathrm{C}_{27} \mathrm{H}_{23} \mathrm{~N}_{2} \mathrm{O}_{5}-455.2$.

\section{Coumarin-pyronin hybrid dye 12}

7-(Dimethylamino)-4-hydroxycoumarin $(88 \mathrm{mg})$ was used as the latent $C$ nucleophile. $\mathrm{N}$-Boc intermediate was purified using the following eluent (a step gradient of $\mathrm{MeOH}$ in DCM from $0 \%$ to $3 \%$ ). The final coumarin-pyronin hybrid dye was purified using the following eluent (a step gradient of $\mathrm{MeOH}$ in $\mathrm{DCM}$ from $0 \%$ to $7 \%$ ) and recovered in a pure form $(65 \mathrm{mg}, 107 \mu \mathrm{mol}$, yield $6 \%$ over three steps, based on TFA mass $=18.7 \%$ determined by ionic chromatography). $\mathrm{R}_{\mathrm{f}}(\mathrm{DCM} / \mathrm{MeOH} 9: 1$ v/v): 0.7; IR (ATR): v = 3321, 3159, 2973, 2927, 1645, 1581, 1545 $1464,1405,1378,1327,1268,1237,1174,1110,1070,1009,991$
$974,915,815,797,769,735,705,650,630 ;{ }^{1} \mathrm{H}$ NMR $(500 \mathrm{MHz}$ $\left.\mathrm{CD}_{3} \mathrm{OD}\right): \delta=7.84\left(\mathrm{~d},{ }^{3} \mathrm{~J}_{\mathrm{H}, \mathrm{H}}=9.0 \mathrm{~Hz}, 1 \mathrm{H}\right), 7.70\left(\mathrm{~d},{ }^{3} \mathrm{~J}_{\mathrm{H}, \mathrm{H}}=9.5 \mathrm{~Hz}, 1 \mathrm{H}\right)$ $7.62\left(\mathrm{~d},{ }^{3} J_{\mathrm{H}, \mathrm{H}}=9.1 \mathrm{~Hz}, 1 \mathrm{H}\right), 7.11\left(\mathrm{dd},{ }^{3} J_{\mathrm{H}, \mathrm{H}}=9.6,{ }^{4} J_{\mathrm{H}, \mathrm{H}}=2.4 \mathrm{~Hz}, 1 \mathrm{H}\right), 6.93$ $\left(\mathrm{d},{ }^{3} J_{\mathrm{H}, \mathrm{H}}=2.4 \mathrm{~Hz}, 1 \mathrm{H}\right), 6.86\left(\mathrm{ddd},{ }^{3} J_{\mathrm{H}, \mathrm{H}}=15.8,{ }^{3} J_{\mathrm{H}, \mathrm{H}}=9.1,{ }^{4} J_{\mathrm{H}, \mathrm{H}}=2.3 \mathrm{~Hz}\right.$ $2 \mathrm{H}), 6.80\left(\mathrm{~d},{ }^{4} J_{\mathrm{H}, \mathrm{H}}=2.1 \mathrm{~Hz}, 1 \mathrm{H}\right), 6.65\left(\mathrm{~d},{ }^{4} J_{\mathrm{H}, \mathrm{H}}=2.4 \mathrm{~Hz}, 1 \mathrm{H}\right), 3.69(\mathrm{q}$ $\left.{ }^{3} J_{\mathrm{H}, \mathrm{H}}=7.0 \mathrm{~Hz}, 4 \mathrm{H}\right), 3.15(\mathrm{~s}, 6 \mathrm{H}), 1.32\left(\mathrm{t},{ }^{3} J_{\mathrm{H}, \mathrm{H}}=7.2 \mathrm{~Hz}, 6 \mathrm{H}\right) ;{ }^{13} \mathrm{C}$ NMR $\left(151 \mathrm{MHz},\left[\mathrm{D}_{6}\right] \mathrm{DMSO}\right): \delta=206.6,161.4,159.2,157.7,157.3,155.7$ $154.8,153.5,132.9,132.4,125.5,116.0,114.5,113.9,113.4,108.4$ 97.2, 96.5, 95.5, 91.2, 45.1, 30.7, $12.5 ;{ }^{19} \mathrm{~F}$ NMR (565 MHz, [D6]DMSO) $\delta=-73.7\left(\mathrm{~s}, 3 \mathrm{~F}, \mathrm{CF}_{3}-\mathrm{TFA}\right.$ ). HPLC (system A): $t_{\mathrm{R}}=4.1 \mathrm{~min}$ (purity $98 \%$ at $260 \mathrm{~nm}, 98 \%$ at $450 \mathrm{~nm}$ and $96 \%$ at $500 \mathrm{~nm})$. LRMS (ESI+, recorded during RP-HPLC analysis): $\mathrm{m} / \mathrm{z} 470.3[\mathrm{M}+\mathrm{H}]^{+}(100)$ and $913.3[2 \mathrm{M}+\mathrm{H}]^{+}$ (9), calcd for $\mathrm{C}_{28} \mathrm{H}_{28} \mathrm{~N}_{3} \mathrm{O}_{4}{ }^{+} 470.2$.

\section{Coumarin-pyronin hybrid dye 13}

7-(Diethylamino)-4-hydroxycoumarin $(100 \mathrm{mg}$ ) was used as the latent $C$ nucleophile. $\mathrm{N}$-Boc intermediate was purified using the following eluent (a step gradient of $\mathrm{MeOH}$ in $\mathrm{DCM}$ from $0 \%$ to $3 \%$ ). The final coumarin-pyronin hybrid dye was purified using the following eluent (a step gradient of $\mathrm{MeOH}$ in $\mathrm{DCM}$ from $0 \%$ to $5 \%$ ) and recovered in a pure form $(79 \mathrm{mg}, 133 \mu \mathrm{mol}, 7 \%$ over three steps, based on TFA mass = $16.1 \%$ determined by ionic chromatography). $\mathrm{R}_{\mathrm{f}}(\mathrm{DCM} / \mathrm{MeOH} 9: 1, \mathrm{v} / \mathrm{v})$ : 0.7 ; IR (ATR): $v=3657,3325,3150,2970,2932,1693,1672,1587$ $1545,1498,1484,1462,1434,1406,1380,1332,1271,1239,1176$, 1114, 1077, 1048, 1011, 977, 935, 907, 837, 818, 795, 771, 739, $719,706,670,647,628 ;{ }^{1} \mathrm{H}$ NMR $\left(500 \mathrm{MHz},\left[\mathrm{D}_{6}\right] \mathrm{DMSO}\right): \delta=7.83(\mathrm{~s}$ $2 \mathrm{H}), 7.68\left(\mathrm{~d},{ }^{3} \mathrm{~J}_{\mathrm{H}, \mathrm{H}}=8.9 \mathrm{~Hz}, 1 \mathrm{H}\right), 7.65-7.58(\mathrm{~m}, 2 \mathrm{H}), 7.04\left(\mathrm{dd},{ }^{3} \mathrm{~J}_{\mathrm{H}, \mathrm{H}}=9.6\right.$, $\left.{ }^{4} J_{\mathrm{H}, \mathrm{H}}=2.5 \mathrm{~Hz}, 1 \mathrm{H}\right), 6.92\left(\mathrm{~d},{ }^{4} \mathrm{~J}_{\mathrm{H}, \mathrm{H}}=2.5 \mathrm{~Hz}, 1 \mathrm{H}\right), 6.82\left(\mathrm{dd},{ }^{3} \mathrm{~J}_{\mathrm{H}, \mathrm{H}}=9.2\right.$ $\left.{ }^{4} J_{\mathrm{H}, \mathrm{H}}=2.1 \mathrm{~Hz}, 1 \mathrm{H}\right), 6.71\left(\mathrm{~d},{ }^{4} J_{\mathrm{H}, \mathrm{H}}=2.1 \mathrm{~Hz}, 1 \mathrm{H}\right), 6.66\left(\mathrm{dd},{ }^{3} J_{\mathrm{H}, \mathrm{H}}=9.2,{ }^{4} J_{\mathrm{H}, \mathrm{H}}\right.$ $=2.5 \mathrm{~Hz}, 1 \mathrm{H}), 6.47\left(\mathrm{~d},{ }^{4} \mathrm{~J}_{\mathrm{H}, \mathrm{H}}=2.4 \mathrm{~Hz}, 1 \mathrm{H}\right), 3.63\left(\mathrm{q},{ }^{3} J_{\mathrm{H}, \mathrm{H}}=7.1 \mathrm{~Hz}, 4 \mathrm{H}\right)$, $3.45\left(\mathrm{q},{ }^{3} \mathrm{~J}_{\mathrm{H}, \mathrm{H}}=7.0 \mathrm{~Hz}, 4 \mathrm{H}\right), 1.21\left(\mathrm{t},{ }^{3} \mathrm{~J}_{\mathrm{H}, \mathrm{H}}=7.0 \mathrm{~Hz}, 6 \mathrm{H}\right), 1.15\left(\mathrm{t},{ }^{3} \mathrm{~J}_{\mathrm{H}, \mathrm{H}}=\right.$ $7.0 \mathrm{~Hz}, 6 \mathrm{H}) ;{ }^{13} \mathrm{C}$ NMR $\left(151 \mathrm{MHz},\left[\mathrm{D}_{6}\right] \mathrm{DMSO}\right): \delta=206.5,161.2,159.3$, $159.2,157.8,157.3,156.1,154.9,151.1,132.7,125.7,116.2,114.5$ $114.0,113.6,108.2,96.6,96.5,95.6,91.2,45.2,44.1,30.7,12.4 ;{ }^{19} \mathrm{~F}$ NMR (565 MHz, [D6]DMSO): $\delta=-73.7$ (s, 3F, CF - TFA); HPLC (system A): $t_{R}=4.3 \min$ (purity $96 \%$ at $260 \mathrm{~nm},>99 \%$ at $450 \mathrm{~nm}$ and $>99 \%$ at $500 \mathrm{~nm}$ ); LRMS (ESI+, recorded during RP-HPLC analysis): $\mathrm{m} / \mathrm{z} 498.1$ $[\mathrm{M}+\mathrm{H}]^{+}(100)$, calcd for $\mathrm{C}_{30} \mathrm{H}_{32} \mathrm{~N}_{3} \mathrm{O}_{4}{ }^{+}$498.2; LRMS (ESI-, recorded during RP-HPLC analysis): $\mathrm{m} / \mathrm{z} 496.2$ [M $\left.^{-}\right]^{-}$(100), calcd for $\mathrm{C}_{30} \mathrm{H}_{30} \mathrm{~N}_{3} \mathrm{O}_{4}-496.2$

\section{Coumarin-pyronin hybrid dye 14}

Please note: minor modification of the synthesis scale brought compared to general procedure described above. Impure bis-aryl ether $10(50 \mathrm{mg}$, $0.13 \mathrm{mmol}$, 1 equiv.) was directly dissolved in absolute $\mathrm{EtOH}(4 \mathrm{~mL})$ and 4-hydroxy derivative of coumarin $6 \mathrm{H}$, used as latent $\mathrm{C}$-nucleophile (35 $\mathrm{mg}, 0.14 \mathrm{mmol}, 1.05$ equiv.), anhydrous $\mathrm{Na}_{2} \mathrm{SO}_{4}(15 \mathrm{mg})$ and piperidine (1 drop) were added. $\mathrm{N}$-Boc intermediate was purified using the following eluent (a step gradient of $\mathrm{MeOH}$ in $\mathrm{DCM}$ from $0 \%$ to $3 \%$ ). The final coumarin-pyronin hybrid dye was purified using the following eluent (a step gradient of $\mathrm{MeOH}$ in $\mathrm{DCM}$ from $0 \%$ to $4 \%$ ) and recovered in a pure form $(20.5 \mathrm{mg}, 28 \mu \mathrm{mol}, 5 \%$ over three steps, based on TFA mass = $32.3 \%$ determined by ionic chromatography). $\mathrm{R}_{\mathrm{f}}(\mathrm{DCM} / \mathrm{MeOH} 9: 1, \mathrm{v} / \mathrm{v})$ 0.8 ; IR (ATR): $v=3335,3215,2962,2850,1646,1587,1548,1512$ $1478,1429,1408,1332,1260,1242,1176,1072,1010,910,795$, 704, 656; ${ }^{1} \mathrm{H}$ NMR $\left(500 \mathrm{MHz}, \mathrm{CD}_{3} \mathrm{OD}\right): \delta=7.65\left(\mathrm{~d},{ }^{3} \mathrm{~J}_{\mathrm{H}, \mathrm{H}}=9.5 \mathrm{~Hz}, 1 \mathrm{H}\right)$ $7.58\left(\mathrm{~d},{ }^{3} J_{\mathrm{H}, \mathrm{H}}=9.1 \mathrm{~Hz}, 1 \mathrm{H}\right), 7.43(\mathrm{~s}, 1 \mathrm{H}), 7.14\left(\mathrm{dd},{ }^{3} J_{\mathrm{H}, \mathrm{H}}=9.6,{ }^{4} J_{\mathrm{H}, \mathrm{H}}=2.5\right.$ $\mathrm{Hz}, 1 \mathrm{H}), 6.98\left(\mathrm{~d},{ }^{4} \mathrm{~J}_{\mathrm{H}, \mathrm{H}}=2.4 \mathrm{~Hz}, 1 \mathrm{H}\right), 6.90\left(\mathrm{dd},{ }^{3} J_{\mathrm{H}, \mathrm{H}}=9.1,{ }^{4} \mathrm{~J}_{\mathrm{H}, \mathrm{H}}=2.1 \mathrm{~Hz}\right.$, $1 \mathrm{H}), 6.83\left(\mathrm{~d},{ }^{4} \mathrm{~J}_{\mathrm{H}, \mathrm{H}}=2.1 \mathrm{~Hz}, 1 \mathrm{H}\right), 3.71\left(\mathrm{q},{ }^{3} \mathrm{~J}_{\mathrm{H}, \mathrm{H}}=7.2 \mathrm{~Hz}, 4 \mathrm{H}\right), 3.39$ (q, $\left.3 J_{\mathrm{H}, \mathrm{H}}=3.3 \mathrm{~Hz}, 4 \mathrm{H}\right), 2.95\left(\mathrm{t}, 3 \mathrm{~J}_{\mathrm{H}, \mathrm{H}}=6.4 \mathrm{~Hz}, 2 \mathrm{H}\right), 2.85\left(\mathrm{t}, 3 \mathrm{~J}_{\mathrm{H}, \mathrm{H}}=6.3 \mathrm{~Hz}\right.$ $2 \mathrm{H}), 2.11-1.95(\mathrm{~m}, 4 \mathrm{H}), 1.33\left(\mathrm{t},{ }^{3} \mathrm{~J}_{\mathrm{H}, \mathrm{H}}=7.3 \mathrm{~Hz}, 6 \mathrm{H}\right) ;{ }^{13} \mathrm{C} \mathrm{NMR}(151 \mathrm{MHz}$ [D6]DMSO): $\delta=206.5,160.8,159.5,157.9,157.4,155.1,151.0,146.7$, $132.3,131.7,121.1,117.9,116.6,114.6,114.1,105.3,96.8,95.8,91.1$ $56.0,49.34,48.8,45.2,27.1,21.0,20.1,20.1,12.5 ;{ }^{19} \mathrm{~F} \mathrm{NMR}(565 \mathrm{MHz}$ [D6]DMSO): $\delta=-73.9\left(\mathrm{~s}, 3 \mathrm{~F}, \mathrm{CF}_{3}\right.$-TFA); HPLC (system A): $t_{\mathrm{R}}=4.5 \mathrm{~min}$ (purity $97 \%$ at $260 \mathrm{~nm}, 97 \%$ at $450 \mathrm{~nm}$ and $98 \%$ at $500 \mathrm{~nm}$ ); LRMS (ESI+, recorded during RP-HPLC analysis): $m / z 522.2[\mathrm{M}+\mathrm{H}]^{+}(100)$, calcd for $\mathrm{C}_{32} \mathrm{H}_{32} \mathrm{~N}_{3} \mathrm{O}_{54}{ }^{+}$522.2; LRMS (ESI-, recorded during RP-HPLC analysis): $\mathrm{m} / \mathrm{z} 520.2[\mathrm{M}-\mathrm{H}]^{-}$(100), calcd for $\mathrm{C}_{32} \mathrm{H}_{30} \mathrm{~N}_{3} \mathrm{O}_{4}{ }^{-} 520.2$.

\section{Calculation of dark TBET efficiency}

The method proposed by Chen et al.[22] was used to calculate the ETEs for coumarin-pyronin hybrids 9 and 11 . 


\section{$\mathrm{ETE}=\left(\mathrm{I}-\mathrm{I}_{0} \%\right) /\left(\mathrm{I}_{100 \%}-\mathrm{I}_{0} \%\right)$}

in which $\mathrm{I}$ is the measured integral of the emission spectrum of the cassette excited at the same wavelength of $10 \%$.

$1_{0} \%=$ the integral of the emission spectrum of the cassette excited at the donor absorption peak. $10 \%$ can be calculated from the following equation:

$$
I_{0 \%}=\left(\Phi_{C} / \Phi_{A}\right) \times I_{A}
$$

in which $\Phi_{\mathrm{A}}$ is the quantum yield of the acceptor excited at the absorption peak of the acceptor, $\Phi_{C}$ is the quantum yield of the cassette excited at the same wavelength of $\Phi_{A}$, and $I_{A}$ is the integral of the emission spectrum of the acceptor excited at the donor absorption peak.

For cassette 9, $\Phi_{\mathrm{A}}=$ quantum yield of PY $\mathbf{B}(59 \%)$ and $\Phi_{\mathrm{C}}=$ quantum yield of $9(84 \%)$, both determined in $\mathrm{CHCl}_{3} ; \mathrm{I}_{\mathrm{A}}=$ integral of emission curve of PY $B$ within the range $320-800 \mathrm{~nm}$ upon excitation at $310 \mathrm{~nm}\left(\mathrm{I}_{\mathrm{A}}\right.$ $=365), I_{0} \%=520$. For cassette 11, $\Phi_{\mathrm{A}}=$ quantum yield of AR116 $(24 \%)$ and $\Phi_{\mathrm{C}}=$ quantum yield of $11(37 \%)$, both determined in $\mathrm{CHCl}_{3} ; \mathrm{I}_{\mathrm{A}}=$ integral of emission curve of AR116 within the range 320-800 nm upon excitation at $310 \mathrm{~nm}\left(\mathrm{I}_{\mathrm{A}}=395\right), \mathrm{I}_{0} \%=608.7$.

The integral of the emission spectrum $\left.\right|_{100 \%}$ of the cassette can be calculated using the following equation:

$$
\mathrm{I}_{100 \%}=\left(\mathrm{A}_{C} / \mathrm{A}_{\mathrm{A}}\right) \times\left(\Phi_{C} / \Phi_{\mathrm{A}}\right) \times \mathrm{I}_{\mathrm{A}}
$$

where $A_{c}$ is the absorbance of the cassette at the wavelength of the donor absorption peak, and $A_{A}$ is the absorbance of the acceptor at the same wavelength of $A_{c}$.

For cassette 9, at a concentration of $2.5 \mu \mathrm{M}, \mathrm{Ac}_{\mathrm{C}}(310 \mathrm{~nm})=0.085$ and $\mathrm{A}_{A}$ $(310 \mathrm{~nm})=0.02 . \mathrm{I}_{100 \%}=2254$. For cassette 11 , at a concentration of 4.5 $\mu \mathrm{M}, \mathrm{A}_{\mathrm{C}}(310 \mathrm{~nm})=0.11$ and $\mathrm{A}_{\mathrm{A}}(310 \mathrm{~nm})=0.04 . \mathrm{I}_{100 \%}=1528$.

For cassette 9, I $(320-800 \mathrm{~nm}$, Ex at $310 \mathrm{~nm})=1598$; ETE $=0.62$ (or $62 \%)$. For cassette 11, I $(320-800 \mathrm{~nm}$, Ex at $310 \mathrm{~nm})=1533$; ETE $=1.0$ (or 100\%).

\section{Computational details}

Our theoretical calculations have been performed with a known protocol[31], combining the results of TD-DFT and second-order wavefunction approaches. All (ground and excited state) structures have been fully optimized at the M06-2X/6-31+G(d) leve[[32], modelling solvent effects using the well-known PCM model[33]. The minimum nature of these structures has been systematically confirmed by analytic Hessian calculations performed at the same PCM-M06-2X/6-31+G(d) level of theory. The relative energies of the various possible tautomers or forms, given in kcal. mol ${ }^{-1}$ in the text, are free energies obtained at this PCMM06-2X/6-31+G(d) level. Next, we have determined vertical transition energies (absorption and emission) using a larger atomic basis set namely $6-311+G(2 d, p)$ and the same functional. These vertical transition energies again account for solvent effects with PCM and we have applied here the so-called LR+cLR approach ${ }^{[34]}$ in its non-equilibrium limit so as to account for both linear-response and state-specific solvation effects. The choice of M06-2X for these TD-DFT calculations is justified by earlier benchmarks showing that this hybrid functional provides a good compromise for various types of excited states[31],[35]. However, as many transitions have a cyanine or a CT nature, TD-DFT is known to have limits and all our transition energies have been corrected with gas-phase CC2/aug-cc-pVDZ ${ }^{[36]}$ following:

$$
\Delta E^{\mathrm{TBE}}=\Delta E_{\mathrm{LR}+\mathrm{cLR}}^{\mathrm{TD}-\mathrm{M} 06-2 \mathrm{X}}+\left(\Delta E_{\mathrm{gas}}^{\mathrm{CC} 2}-\Delta E_{\text {gas }}^{\mathrm{TD}-\mathrm{M} 06-2 \mathrm{X}}\right)
$$

To identify the corresponding states at the various levels of theory, we have used the usual approaches (energies, MO composition, $f, \ldots$ ), which was straightforward in most cases. When $\mathrm{MO}$ mixing was significant for two low close-lying transitions, we considered the lowest possible. While such additive model provides a ca. $\pm 0.15 \mathrm{eV}$ accuracy[31],[35], it should be recalled that the vertical transition energies are not $\lambda_{\max }$ or $\lambda_{\mathrm{fl}}$, as vibronic effects are neglected ${ }^{[37]}$, hence we do not strive here for exactly reproducing these experimental values but rather to rationalize the experimental outcomes and trends. To quantify the CT effects, we used Le Bahers' model[ ${ }^{[38]}$, that is based on the analysis of the barycenters of density gain and depletion upon transition. This model was applied using TD-DFT electronic densities. The DFT and TD-DFT calculations have been performed with Gaussian 16.A.03[39], using default procedure, but for tightened SCF and residual force convergence criteria. The SMD-MP2 calculations have been performed with the same code. All second-order coupled-cluster calculations have been made with the Turbomole $7.11 /$ T.3 code $^{[40]}$, applying the RI-V approach.

\section{Cell imaging}

A549 cells were seeded on Lab-Tek ${ }^{\text {TM }}$ chamber slides, 8 wells (Thermo Fisher Scientific) and grown in RPMI-1640 medium containing 10\% fetal calf serum (FCS) and 1\% glutamine. After reaching enough confluence, they were incubated for $2 \mathrm{~h}$ with rosamine 9 or 11 at the selected concentration $(5 \mu \mathrm{M})$ in RPMI medium. Cells were then fixed for $15 \mathrm{~min}$ with 4\% paraformaldehyde solution in PBS (1X) at RT (for more experimental details see the Supporting Information). Fluorescence images were acquired using a Leica SPX-8 inverted confocal microscope with $40 \times$ oil immersion objective (HC PL HPO CS2 Leica).

\section{Acknowledgements}

This work is supported by the CNRS, Universite de Bourgogne and Conseil Régional de Bourgogne through the "Plan d'Actions Régional pour l'innovation (PARI)" and the "Fonds Européen de Développement Régional (FEDER)" programs. Financial supports from Agence Nationale de la Recherche (ANR, AAPG 2018, PRCI LuminoManufacOligo, ANR-18-CE07-0045-01), especially for the post-doc fellowship of K. R., and the National Research Foundation Singapore (NRF, LuminoManufacOligo, NRF2018-NRF-ANR035) are also greatly acknowledged. GDR CNRS "Agents d'Imagerie Moléculaire" (AIM) 2037 is also thanked for its interest in this research topic. A. R. and K. R. thank the "Plateforme d'Analyse Chimique et de Synthèse Moléculaire de l'Université de Bourgogne" (PACSMUB, http://www.wpcm.fr) for access to spectroscopy instrumentation. COBRA lab (UMR CNRS 6014) and Iris Biotech company are warmly thanked for the generous gift of some chemical reagents used in this work. The authors also thank Dr. Myriam Laly (University of Burgundy, PACSMUB) for the determination of TFA content in fluorophore samples, Prof. Ewen Bodio (University of Burgundy, ICMUB, UMR CNRS 6302, OCS team) for access to SAFAS Flx-Xenius XC spectrofluorimeter, Misses Asmae Bousfiha and Jihane Bousfiha ( $1^{\text {st }}$ year master students, University of Burgundy, 2015-2016) for the synthesis of pyronin B, and Dr. Valentin Quesneau (UBFC, ICMUB) for critical reading and relevant comments on this manuscript before publication and recrystallization of commercial 4(diethylamino)salicylaldehyde. Prof. Denis Jacquemin is indebted to the CCIPL HPC center installed in Nantes for generous allocation of computational resources.

Keywords: ab initio calculation • coumarins $•$ fluorescent probes - hybrid fluorophores $\cdot$ pyronins $\cdot$ rosamines 
[1] L. D. Lavis, Annu. Rev. Biochem. 2017, 86, 825-843.

[2] For selected reviews: a) H. N. Kim, M. H. Lee, H. J. Kim, J. S. Kim, J. Yoon, Chem. Soc. Rev. 2008, 37, 1465-1472; b) M. Beija, C. A. M. Afonso, J. M. G. Martinho, Chem. Soc. Rev. 2009, 38, 2410-2433; c) X. Chen, T. Pradhan, F. Wang, J. S. Kim, J. Yoon, Chem. Rev. 2012, 112, 1910-1956; d) H. Zheng, X.-Q. Zhan, Q.-N. Bian, X.-J. Zhang, Chem. Commun. 2013, 49, 429-447; e) M. Fu, X. Zhang, J. Wang, H. Chen, Y. Gao, Curr. Org. Chem. 2016, 20, 1584-1590; f) R. Zhang, F. Yan, Y. Huang, D. Kong, Q. Ye, J. Xu, L. Chen, RSC Adv. 2016, 6, 50732-50760; g) S. G. Keller, M. Kamiya, Y. Urano, Molecules 2020, 25, 5964.

a) M. Sauer, K. T. Han, R. Mueller, S. Nord, A. Schulz, S Seeger, J. Wolfrum, J. Arden-Jacob, G. Deltau, et al., J. Fluoresc. 1995, 5, 247-261; b) A. Macho, D. Decaudin, M. Castedo, T. Hirsch, S. A. Susin, N. Zamzami, G. Kroemer, Cytometry 1996, 25, 333-340; c) T. Minamikawa, A Sriratana, D. A. Williams, D. N. Bowser, J. S. Hill, P. Nagley, J. Cell Sci. 1999, 112, 2419-2430; d) R. Bandichhor, A. D. Petrescu, A. Vespa, A. B. Kier, F. Schroeder, K. Burgess, Bioconjugate Chem. 2006, 17, 1219-1225; e) Y.-H. Ahn, J.-S. Lee, Y.-T. Chang, J. Am. Chem. Soc. 2007, 129, 4510-4511; f) Y.-H. Ahn, J.-S. Lee, Y.-T. Chang, J. Comb. Chem. 2008, 10, 376-380; g) S. Iyoshi, M. Taki, Y. Yamamoto, Inorg. Chem. 2008, 47, 3946-3948; h) L. Wu, K Burgess, J. Org. Chem. 2008, 73, 8711-8718; i) J.-S. Lee, Y K. Kim, M. Vendrell, Y.-T. Chang, Mol. BioSyst. 2009, 5, 411-421; j) B. D. Calitree, M. R. Detty, Synlett 2010, 89-92 k) C.-N. Im, N.-Y. Kang, H.-H. Ha, X. Bi, J. Lee Jae, S.-J. Park, Y. Lee Sang, M. Vendrell, K. Kim Yun, J.-S. Lee, J. Li, Y.-H. Ahn, B. Feng, H.-H. Ng, S.-W. Yun, Y.-T. Chang, Angew. Chem., Int. Ed. 2010, 49, 7497-7500; 1) C.-N. Im, N.-Y. Kang, H.-H. Ha, X. Bi, J. J. Lee, S.-J. Park, S. Y. Lee, M. Vendrell, Y. K. Kim, J.-S. Lee, J. Li, Y.-H. Ahn, B. Feng, H.-H. Ng, S.-W. Yun, Y.-T. Chang, Angew. Chem., Int. Ed. 2010, 49, 7497-7500; m) Y. K. Kim, H.-H. Ha, J.-S. Lee, X. Bi, Y.-H. Ahn, S. Hajar, J.-J. Lee, Y.-T. Chang, J. Am. Chem. Soc. 2010, 132, 576-579; n) J. Li, H.-H. Ha, L. Guo, D. Coomber, Y.-T. Chang, Chem. Commun. 2010, 46, 29322934; o) Y. K. Kim, J.-S. Lee, X. Bi, H.-H. Ha, S. H. Ng, Y.-h. Ahn, J.-J. Lee, B. K. Wagner, P. A. Clemons, Y.-T. Chang, Angew. Chem., Int. Ed. 2011, 50, 2761-2763; p) I. C. S. Cardoso, A. L. Amorim, C. Queirós, S. C. Lopes, P. Gameiro, B. de Castro, M. Rangel, A. M. G. Silva, Eur. J. Org. Chem. 2012, 2012, 5810-5817; q) J.-S. Lee, Y. K. Kim, H. J. Kim, S. Hajar, Y. L. Tan, N.-Y. Kang, S. H. Ng, C. N. Yoon, Y.-T. Chang, PLoS One 2012, 7, e32096; r) M. Hu, J. Fan, J. Cao, K. Song, H. Zhang, S. Sun, X. Peng, Analyst 2012, 137, 2107-2111; s) E. Ko, A. Kamkaew, K. Burgess, ACS Med. Chem. Lett. 2012, 3, 1008-1012; t) M. Taki, K. Akaoka, S. Iyoshi, Y. Yamamoto, Inorg. Chem. 2012, 51, 13075-13077; u) J. J. Strouse, I. Ivnitski-Steele, A. Waller, S M. Young, D. Perez, A. M. Evangelisti, O. Ursu, C. G. Bologa, M. B. Carter, V. M. Salas, G. Tegos, R. S. Larson, T. I. Oprea, B. S. Edwards, L. A. Sklar, Anal. Biochem. 2013, 437, 77-87; v) J. Vukovic, A.-S. Bedin, P. F. Bartlett, G. W. Osborne, Stem Cells Dev. 2013, 22, 2341-2345; w) M. M. Haque, D. Kim, Y. H. Yu, S. Lim, D. J. Kim, Y.-T. Chang, H.-H. Ha, Y. K. Kim, Amyloid 2014, 21, 185-190; x) G. A Kraus, T. Guney, A. Kempema, J. M. Hyman, B. Parvin, Tetrahedron Lett. 2014, 55, 1549-1551; y) C. Queiros, A. Leite, M. G. M. Couto, L. Cunha-Silva, G. Barone, B. de Castro, M. Rangel, A. M. N. Silva, A. M. G. Silva, Chem. Eur. J. 2015, 21, 15692-15704; z) J. Cheng, J. Song, H. Niu, J. Tang, D. Zhang, Y. Zhao, Y. Ye, New J. Chem. 2016, 40,
6384-6388; aa) O. Dilek, S. L. Bane, Chemosensors 2016, 4, 5/1-5/8; ab) L.-Q. Li, L.-J. Gao, Spectrochim. Acta, Part A 2016, 152, 426-430; ac) D. Zhang, W. Liu, K. Chen, J. Cheng, Y. Zhao, Y. Ye, RSC Adv. 2016, 6, 103905-103909; ad) H. Okuno, N. Ieda, Y. Hotta, M. Kawaguchi, K. Kimura, H. Nakagawa, Org. Biomol. Chem. 2017, 15, 2791-2796; ae) L. Yang, J.-Y. Niu, R. Sun, Y.-J. Xu, J.-F. Ge, Org. Biomol. Chem. 2017, 15, 8402-8409; af) A. Novais, T. Moniz, A. R. Rebelo, A. M. G. Silva, M. Rangel, L. Peixe, Bioorg. Chem. 2018, 79, 341-349; ag) C. Queiros, A. Leite, L. Cunha-Silva, B. de Castro, M. Rangel, A. Sousaraei, J. CabanillasGonzalez, F. Gamez, E. Jamardo, A. P. Vargas, F. G. Moscoso, T. Lopes-Costa, J. M. Pedrosa, A. M. G. Silva, Dyes Pigm. 2018, 157, 405-414; ah) A. Sajid, S. Lusvarghi, E. E. Chufan, S. V. Ambudkar, PLoS One 2018, 13, e0204693; ai) L. Yang, J. Niu, Y. Zhan, Y. Xu, R. Sun, J. Ge, Chin. J. Chem. 2018, 36, 42-46; aj) N. Ieda, Y. Oka, T. Yoshihara, S. Tobita, T. Sasamori, M. Kawaguchi, H. Nakagawa, Sci. Rep. 2019, 9, 1-8.

[4] For a comprehensive review, see: Y. M. Poronik, K. V. Vygranenko, D. Gryko, D. T. Gryko, Chem. Soc. Rev. 2019, 48, 5242-5265.

[5] For selected reviews, see: a) H. Chen, B. Dong, Y. Tang, W. Lin, Acc. Chem. Res. 2017, 50, 1410-1422; b) F. Deng, Z. Xu, Chin. Chem. Lett. 2019, 30, 1667-1681; c) M. Li, Y. Li, X. Wang, X. Cui, T. Wang, Chin. Chem. Lett. 2019, 30, 1682-1688; d) L. Wang, W. Du, Z. Hu, K. Uvdal, L. Li, W. Huang, Angew. Chem., Int. Ed. 2019, 58, 14026-14043.

[6] a) W. Piao, S. Tsuda, Y. Tanaka, S. Maeda, F. Liu, S. Takahashi, Y. Kushida, T. Komatsu, T. Ueno, T. Terai, T. Nakazawa, M. Uchiyama, K. Morokuma, T. Nagano, K. Hanaoka, Angew. Chem., Int. Ed. 2013, 52, 13028-13032; b) R. Sun, X.-D. Liu, Z. Xun, J.-M. Lu, Y.-J. Xu, J.-F. Ge, Sens. Actuators, B 2014, 201, 426-432; c) P. Shieh, V. T. Dien, B. J. Beahm, J. M. Castellano, T. Wyss-Coray, C. R. Bertozzi, J. Am. Chem. Soc. 2015, 137, 7145-7151; d) N. Shin, K. Hanaoka, W. Piao, T. Miyakawa, T. Fujisawa, S. Takeuchi, S. Takahashi, T. Komatsu, T. Ueno, T. Terai, T. Tahara, M. Tanokura, T. Nagano, Y. Urano, ACS Chem. Biol. 2017, 12, 558-563; e) Y. Wang, L. Yang, X.-R. Wei, R. Sun, Y.-J. Xu, J.-F. Ge, Anal. Methods 2018, 10, 5291-5296; f) L. Yang, J.Y. Niu, R. Sun, Y.-J. Xu, J.-F. Ge, Analyst 2018, 143, 18131819; g) L. Yang, J.-Y. Niu, R. Sun, Y.-J. Xu, J.-F. Ge, Sens. Actuators, B 2018, 259, 299-306; h) A. Leite, L. CunhaSilva, D. Silva, A. I. M. C. Lobo Ferreira, L. M. N. B. F. Santos, I. C. S. Cardoso, V. L. M. Silva, M. Rangel, A. M. G. Silva, Chem. - Eur. J. 2019, 25, 15073-15082; i) Y. Zhao, Y. Xue, J. Sun, H. Xuan, Y. Xu, Y. Cui, J. Dong, New J. Chem. 2020, 44, 12674-12679.

[7] a) J. Fan, M. Hu, P. Zhan, X. Peng, Chem. Soc. Rev. 2013, 42, 29-43; b) D. Cao, L. Zhu, Z. Liu, W. Lin, J. Photochem. Photobiol. C 2020, 44, 100371.

[8] a) W. Lin, L. Yuan, Z. Cao, Y. Feng, J. Song, Angew. Chem., Int. Ed. 2010, 49, 375-379; b) S. Saha, P. Mahato, M. Baidya, S. K. Ghosh, A. Das, Chem. Commun. 2012, 48, 9293-9295; c) J. X. Ong, V. Y. T. Pang, L. M. Tng, W. H. Ang, Chem. - Eur. J. 2018, 24, 1870-1876.

[9] W. Lin, L. Long, W. Tan, B. Chen, L. Yuan, Chem. - Eur. J. 2010, 16, 3914-3917.

[10] X. Luo, L. Qian, Y. Xiao, Y. Tang, Y. Zhao, X. Wang, L. Gu, Z. Lei, J. Bao, J. Wu, T. He, F. Hu, J. Zheng, H. Li, W. Zhu, L. Shao, X. Dong, D. Chen, X. Qian, Y. Yang, Nat. Commun. 2019, 10, 258.

[11] S. Clunas, J. M. D. Strory, J. E. Rickard, D. Horsley, C. R. Harrington, C. M. Wischik, (WisTa Laboratories Ltd., Singapore), WO2010067078, 2010. 

Gholamzadeh, Mol. Divers. 2019, 23, 1029-1064.

[13] S. Mondal, A. Verma, S. Saha, Eur. J. Org. Chem. 2019 2019, 864-894.

[14] Z. Lei, X. Li, Y. Li, X. Luo, M. Zhou, Y. Yang, J. Org. Chem. 2015, 80, 11538-11543.

[15] K. Renault, S. Debieu, J.-A. Richard, A. Romieu, Org. Biomol. Chem. 2019, 17, 8918-8932.

[16] T. He, H. He, X. Luo, Y. Yang, Y. Yang, Sci. Sinica Chim. 2017, 47, 945-954.

[17] a) Z. Lei, Y. Yang, J. Am. Chem. Soc. 2014, 136, 65946597 ; b) L. Song, Z. Lei, B. Zhang, Z. Xu, Z. Li, Y. Yang, Anal. Methods 2014, 6, 7597-7600; c) S. Debieu, A. Romieu, Org. Biomol. Chem. 2017, 15, 2575-2584; d) S. Debieu, A. Romieu, Tetrahedron Lett. 2018, 59, 1940-1944.

[18] A. V. Anzalone, T. Y. Wang, Z. Chen, V. W. Cornish, Angew. Chem., Int. Ed. 2013, 52, 650-654.

[19] D. Escudero, Acc. Chem. Res. 2016, 49, 1816-1824.

[20] M. Ogawa, N. Kosaka, P. L. Choyke, H. Kobayashi, ACS Chem. Biol. 2009, 4, 535-546.

[21] M. P. Shandura, Y. M. Poronik, Y. P. Kovtun, Dyes Pigm. 2007, 73, 25-30.

[22] Y. Chen, W. Zhang, Y. Cai, R. T. K. Kwok, Y. Hu, J. W. Y. Lam, X. Gu, Z. He, Z. Zhao, X. Zheng, B. Chen, C. Gui, B. Z. Tang, Chem. Sci. 2017, 8, 2047-2055.

[23] Y. Jiang, Q. Duan, G. Zheng, L. Yang, J. Zhang, Y. Wang, H. Zhang, J. He, H. Sun, D. Ho, Analyst 2019, 144, 1353 1360.

[24] R. Gui, H. Jin, X. Bu, Y. Fu, Z. Wang, Q. Liu, Coord. Chem. Rev. 2019, 383, 82-103.

[25] A. M. Brouwer, Pure Appl. Chem. 2011, 83, 2213-2228.

[26] X.-F. Zhang, J. Zhang, X. Lu, J. Fluoresc. 2015, 25, 11511158.

[27] S.-H. Park, N. Kwon, J.-H. Lee, J. Yoon, I. Shin, Chem. Soc Rev. 2020, 49, 143-179.

[28] a) A. Chevalier, P.-Y. Renard, A. Romieu, Chem. - Eur. J. 2014, 20, 8330-8337; b) B. Viswanadham, A. S. Mahomed, H. B. Friedrich, S. Singh, Res. Chem. Intermed. 2017, 43, 1355-1363.

[29] G. R. Fulmer, A. J. M. Miller, N. H. Sherden, H. E. Gottlieb, A. Nudelman, B. M. Stoltz, J. E. Bercaw, K. I. Goldberg, Organometallics 2010, 29, 2176-2179.

[30] G. Dejouy, M. Laly, I. E. Valverde, A. Romieu, Dyes Pigm. 2018, 159, 262-274

[31] a) D. Jacquemin, I. Duchemin, X. Blase, J. Chem. Theory Comput. 2015, 11, 5340-5359; b) B. Le Guennic, D. Jacquemin, Acc. Chem. Res. 2015, 48, 530-537.

[32] Y. Zhao, D. G. Truhlar, Theor. Chem. Acc. 2008, 120, $215-$ 241.
[33] a) J. Tomasi, B. Mennucci, R. Cammi, Chem. Rev. 2005, 105, 2999-3094; b) C. A. Guido, S. Caprasecca, Int. J. Quantum Chem. 2019, 119, e25711.

[34] a) R. Cammi, B. Mennucci, J. Chem. Phys. 1999, 110, 98779886; b) M. Caricato, B. Mennucci, J. Tomasi, F. Ingrosso, R. Cammi, S. Corni, G. Scalmani, J. Chem. Phys. 2006, 124, 124520 .

[35] a) M. Isegawa, R. Peverati, D. G. Truhlar, J. Chem. Phys. 2012, 137, 244104; b) S. S. Leang, F. Zahariev, M. S. Gordon, J. Chem. Phys. 2012, 136, 104101; c) D. Jacquemin, I. Duchemin, X. Blase, J. Phys. Chem. Lett. 2017, 8, 15241529.

[36] O. Christiansen, H. Koch, P. Jorgensen, Chem. Phys. Lett. 1995, 243, 409-418.

[37] a) L. Goerigk, S. Grimme, J. Chem. Phys. 2010, 132, 184103/184101-184103/184109; b) F. Santoro, D. Jacquemin, WIREs Comput. Mol. Sci. 2016, 6, 460-486.

[38] a) T. Le Bahers, C. Adamo, I. Ciofini, J. Chem. Theory Comput. 2011, 7, 2498-2506; b) I. Ciofini, T. Le Bahers, C. Adamo, F. Odobel, D. Jacquemin, J. Phys. Chem. C 2012, 116, 11946-11955.

[39] M. J. Frisch, G. W. Trucks, H. B. Schlegel, G. E. Scuseria, M. A. Robb, J. R. Cheeseman, G. Scalmani, V. Barone, G. A. Petersson, H. Nakatsuji, X. Li, M. Caricato, A. V. Marenich, J. Bloino, B. G. Janesko, R. Gomperts, B. Mennucci, H. P. Hratchian, J. V. Ortiz, A. F. Izmaylov, J. L. Sonnenberg, Williams, F. Ding, F. Lipparini, F. Egidi, J. Goings, B. Peng, A. Petrone, T. Henderson, D. Ranasinghe, V. G. Zakrzewski, J. Gao, N. Rega, G. Zheng, W. Liang, M. Hada, M. Ehara, K. Toyota, R. Fukuda, J. Hasegawa, M. Ishida, T. Nakajima, Y. Honda, O. Kitao, H. Nakai, T. Vreven, K. Throssell, J. A. Montgomery Jr., J. E. Peralta, F. Ogliaro, M. J. Bearpark, J. J. Heyd, E. N. Brothers, K. N. Kudin, V. N. Staroverov, T. A. Keith, R. Kobayashi, J. Normand, K. Raghavachari, A. P. Rendell, J. C. Burant, S. S. Iyengar, J. Tomasi, M. Cossi, J. M. Millam, M. Klene, C. Adamo, R. Cammi, J. W. Ochterski, R. L. Martin, K. Morokuma, O. Farkas, J. B. Foresman, D. J. Fox, Gaussian 16 Rev. A.03, Gaussian Inc., Wallingford, CT, 2016

[40] TURBOMOLE V7.1 2016, a development of University of Karlsruhe and Forschungszentrum Karlsruhe GmbH, 19892007, TURBOMOLE GmbH, since 2007; available from http://www.turbomole.com. 


\section{Coumarin-rosamine/rhodamine dyads (TBET cassettes):}
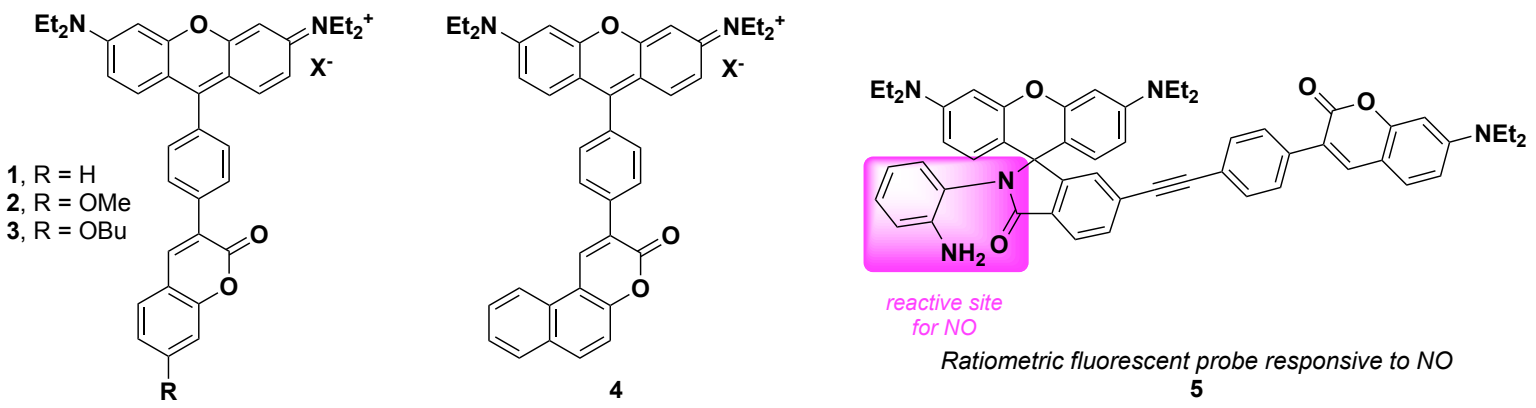

Coumarin-pyronin hybrid dyes (unusual rosmamines):

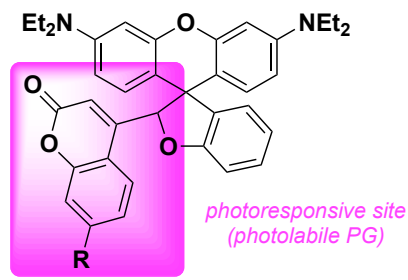

6, $\mathrm{R}=\mathrm{NEt}_{2}$ 7, $\mathrm{R}=\mathrm{OMe}$<smiles>[Y4]c1ccc(-c2cc3ccc(N(C)C)cc3oc2=O)c(-c2ccc(N(C)C)cc2)c1</smiles>

RD42<smiles></smiles>

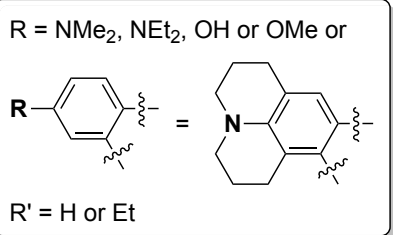

This work

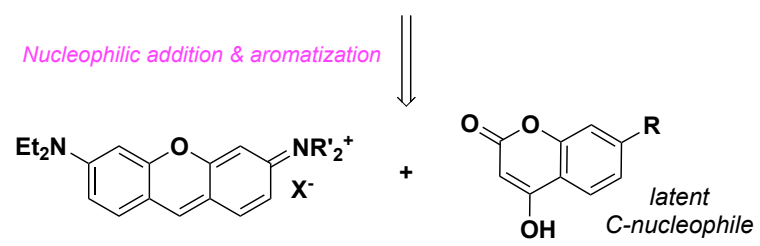

Figure 1. (Top) Structures of coumarin-rosamine/rhodamine dyads reported in the literature and acting as TBET cassettes ${ }^{[\mathrm{aa}, 8 \mathrm{c}]}$. (Bottom) Structures of coumarin-pyronin hybrid dyes reported in the literature ${ }^{[9-10]}$; structures of coumarin-pyronin hybrid dyes studied in the present work and first retrosynthetic strategy initially proposed $\left(\mathrm{X}=\mathrm{Cl}^{-}\right.$for compounds $\mathbf{1 - 4}$ and $\mathbf{R D 4 2}, \mathrm{X}^{-}=\mathrm{Br}^{-}$or $\mathrm{CF}_{3} \mathrm{CO}_{2}{ }^{-}$for rosamines synthesized in the present work, $\mathrm{PG}=$ protecting group). 


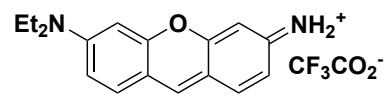

AR116 (TFA salt)

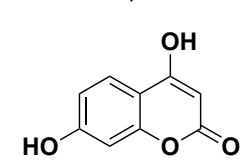

PB-MeCN-DMSO $(2: 1: 1, v / v / v)$ $60^{\circ} \mathrm{C}, 24 \mathrm{~h}$

yield after
RP-HPLC purification $6 \%$
$\mathrm{Et}_{2} \mathrm{~N}$

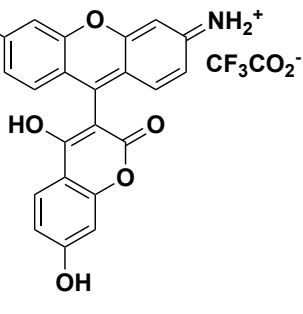

4,7-dihydroxycoumarin<smiles></smiles>

pyronin B ( $\mathrm{HBr}$ salt)

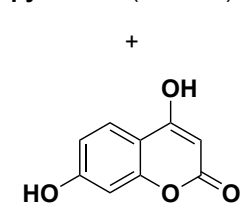

TEA, DMF, $50^{\circ} \mathrm{C}, 22 \mathrm{~h}$

yield after $\mathrm{FC}\left(\mathrm{SiO}_{2}\right)$ \& preparative TLC $\left(\mathrm{SiO}_{2}\right) \mathbf{3 0} \%$

$\mathrm{Et}_{2} \mathrm{~N}$<smiles>CCN=c1ccc2c(-c3c(O)c4ccc(O)cc4oc3=O)c3ccc(I)cc3oc-2c1</smiles>

4,7-dihydroxycoumarin

Scheme 1. Synthesis of coumarin-pyronin hybrid dyes 8 and 9 through single-step pathway from pyronin AR116 (top) or pyronin B (bottom) $\left(\mathrm{PB}=\right.$ phosphate buffer, $100 \mathrm{mM}, \mathrm{pH} 7.5, \mathrm{FC}\left(\mathrm{SiO}_{2}\right)=$ flash-column chromatography over silica gel, TEA = triethylamine, TLC $\left(\mathrm{SiO}_{2}\right)=$ thin layer chromatography over silica gel). 

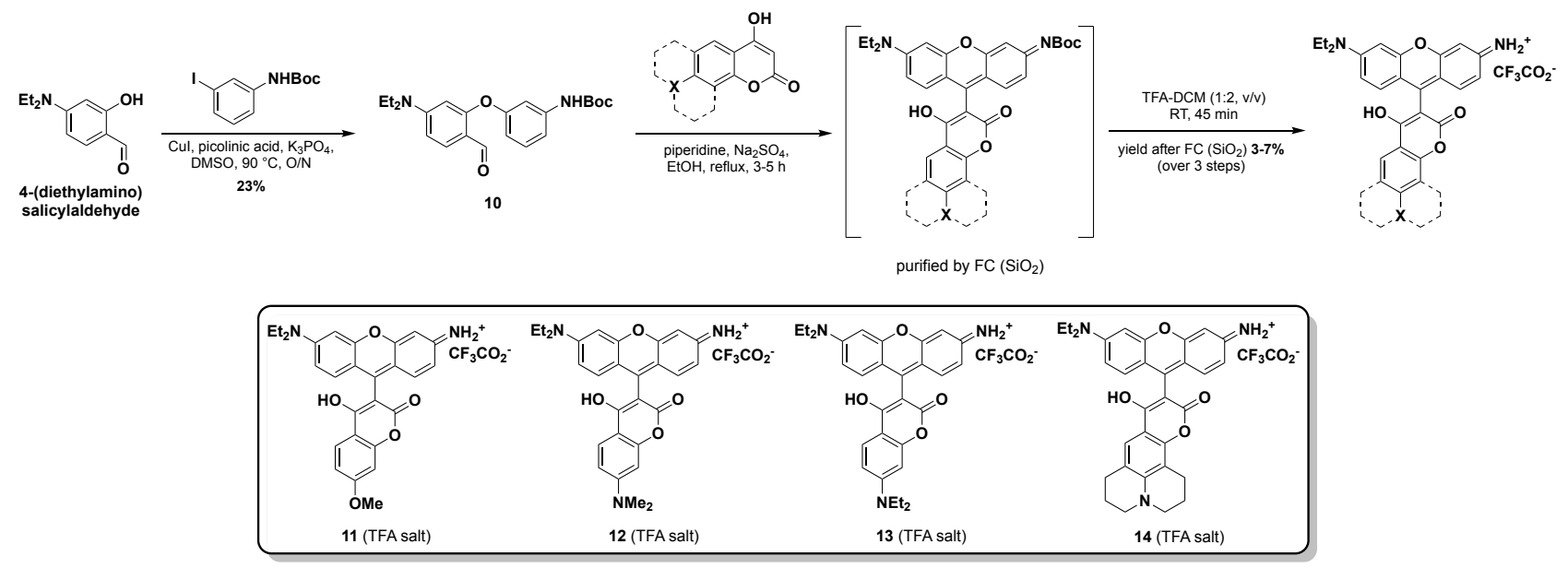

Scheme 2. Synthesis of coumarin-pyronin hybrid dyes 11-14 through three-step pathway from 4-(diethylamino)salicylaldehyde $\left(\mathrm{FC}(\mathrm{SiO})_{2}\right)$ = flash-column chromatography over silica gel, $\mathrm{O} / \mathrm{N}=$ overnight, $\mathrm{RT}=$ room temperature). Please note: rosamine $\boldsymbol{8}$ (see Scheme 1 for the structure) was also prepared using this three-step synthetic pathway (overall yield 5\%). 

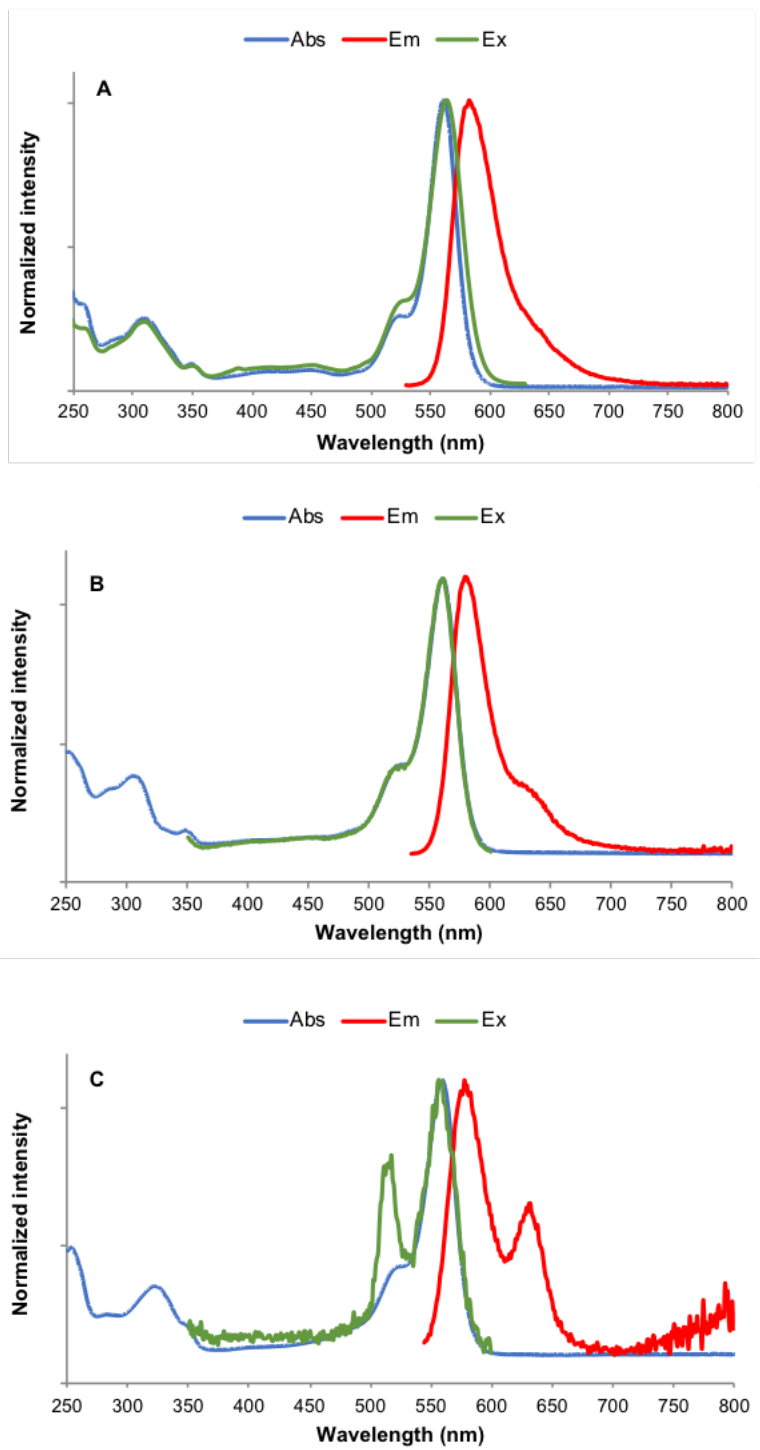
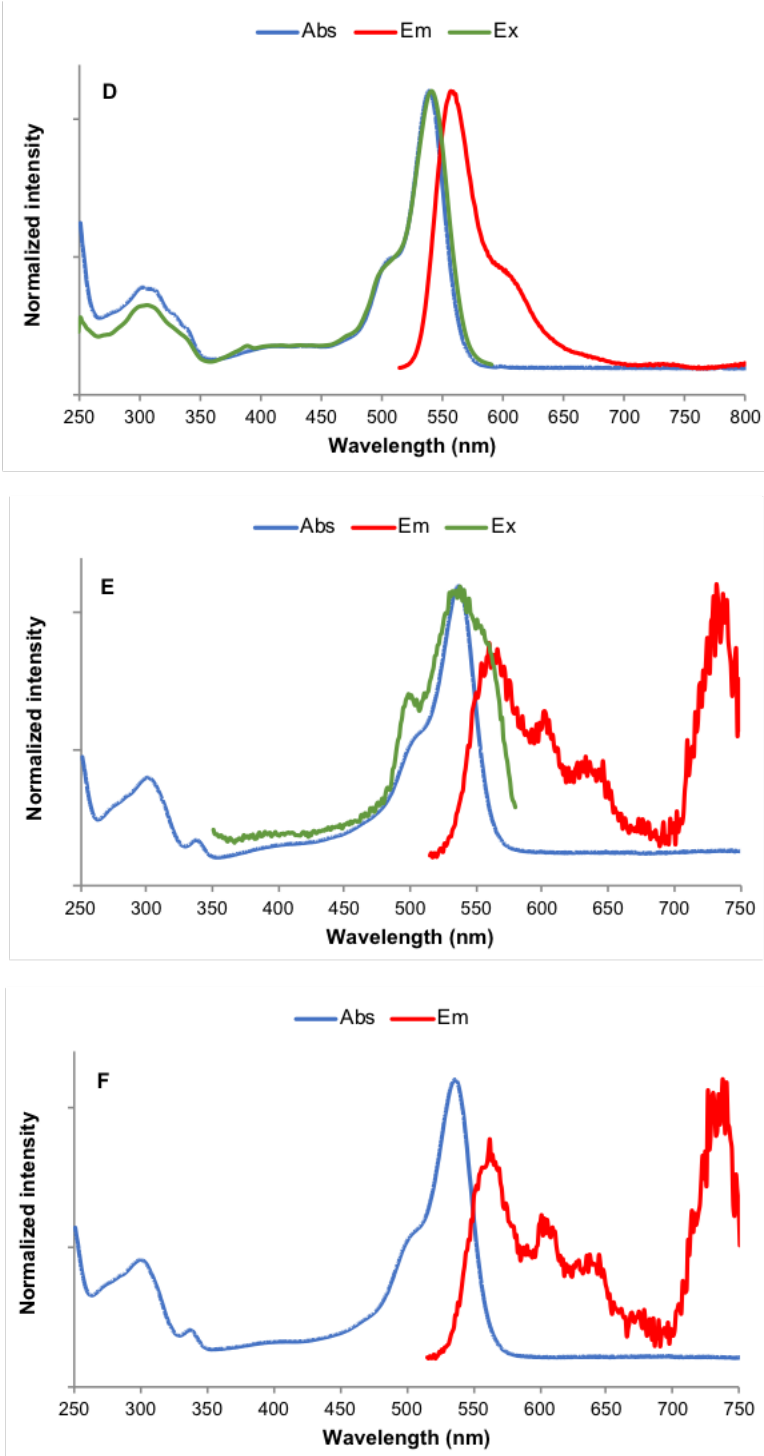

Figure 2. Normalized absorption, fluorescence emission (excitation at $520 \mathrm{~nm}(\mathrm{~A}-\mathrm{C})$ or $500 \mathrm{~nm}$ (D-E)) and excitation (emission at $640 \mathrm{~nm}$ (A), $625 \mathrm{~nm}(\mathrm{~B}-\mathrm{C})$ or $600 \mathrm{~nm}(\mathrm{D}-\mathrm{E})$ ) spectra of rosamine dyes 9 and 11 in $\mathrm{CHCl}_{3}$ (A and D), in $\mathrm{PB} \mathrm{pH} 7.5$ (B and E) and in CB pH 10.2 (C and F) at $25{ }^{\circ} \mathrm{C}$. For compound 9, absorption maximum situated within the range $305-320 \mathrm{~nm}$ (depending on the solvent used) is assigned to the grafted 4,7-dihydroxycoumarin unit; for compound 11, band assigned to the grafted 4-hydroxy-7-methoxycoumarin unit is centered at $300 \mathrm{~nm}$. Please note: compound 11 is very poorly fluorescent in aqueous buffers thus explaining the bad quality of emission/excitation curves. In CB, it was not possible to record the excitation spectrum of 11 since this compound is too weakly fluorescent in this basic buffer. 
Non-fluorescent meso-substituted pyronin B derivatives:<smiles>CCN(CC)c1ccc2c(c1)Oc1cc(N(CC)CC)ccc1C2=C([15NH])C=O</smiles><smiles>CCN(CC)c1ccc2c(c1)Oc1cc(N(CC)CC)ccc1C2=C([14CH3])C#N</smiles>

Keto-enol tautomeric equilibrium of 4-hydroxycoumarin-pyronin hybrid dyes:<smiles>[Z17][NH+]=c1ccc2c(-c3c(O)c4ccc([R])cc4oc3=O)c3ccc(N(CC)CC)cc3oc-2c1</smiles><smiles>[R]c1ccc2c(c1)OC(=O)C(=C1C(=O)c3ccc(N([R12])[R4])cc3Oc3cc(N(CC)CC)ccc31)C2=O</smiles>

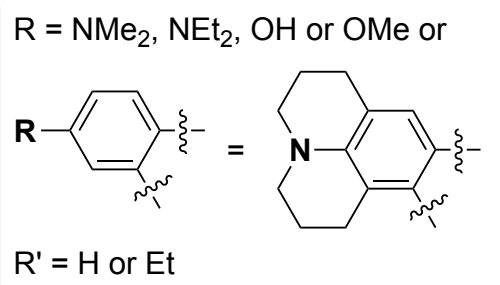

Non-fluorescent form favored in the lack of TFA?

Figure 3. (Top) Structures of non-fluorescent anologs of pyronin B reported by Shandura et al. ${ }^{[21]}$. (Bottom) Proposed keto-enol tautomerization to explain the loss of fluorescence of rosamine dyes 8, 9 and 11-14 upon TFA removal. 

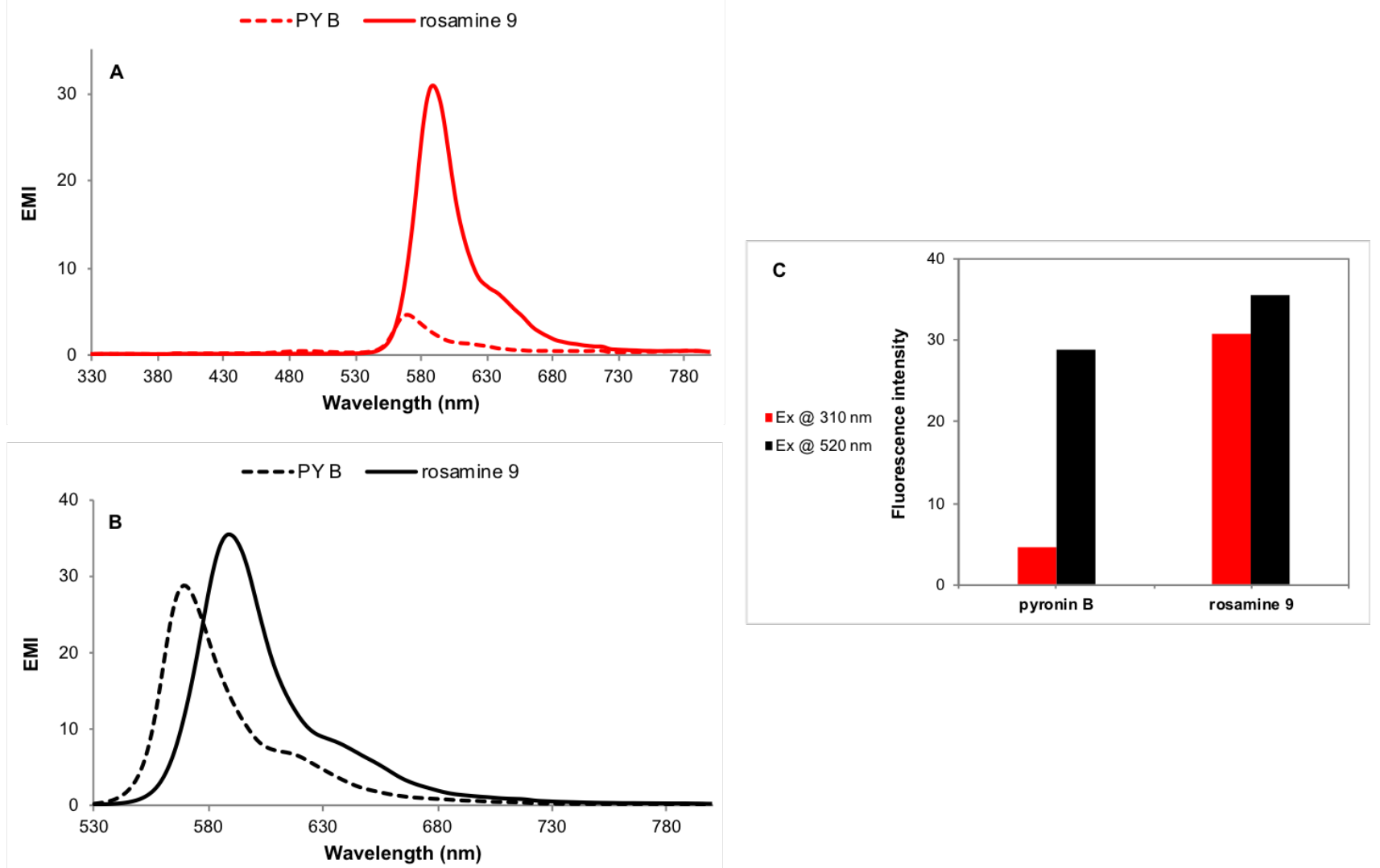

Figure 4. (A) Fluorescence emission spectra of pyronin $\mathrm{B}$ and rosamine 9 in $\mathrm{CHCl}_{3}$ under excitation at $310 \mathrm{~nm}$. (B) Fluorescence emission spectra of pyronin $\mathrm{B}$ and rosamine 9 in $\mathrm{CHCl}_{3}$ under excitation at $520 \mathrm{~nm}$. (C) Plot of fluorescence emission intensity at $569 \mathrm{~nm}$ (for pyronin B) or $589 \mathrm{~nm}$ (for rosamine 9) after excitation at $310 \mathrm{~nm}$ and $520 \mathrm{~nm}$. Dye concentration: $2.5 \mu \mathrm{M}$ (PMT voltage $=395 \mathrm{~V}$ for the recording of emission spectra). 
Modelled structures for rosamine 11:

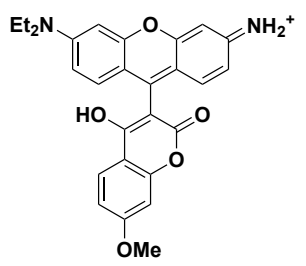

11(C)
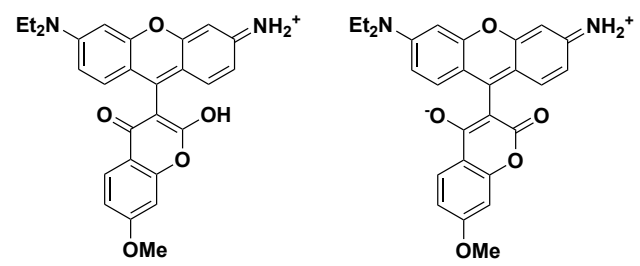

11(CT)
11(Z)<smiles>CCN(CC)c1ccc2c(-c3c(O)c4ccc(OC)cc4oc3=O)c3ccc(=N)cc-3oc2c1</smiles>

$11(N)$

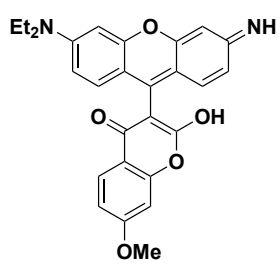

11(T)

Figure 5. Representation of the various forms of rosamine 11 studied with theory.

$\mathrm{CHCl}_{3}$

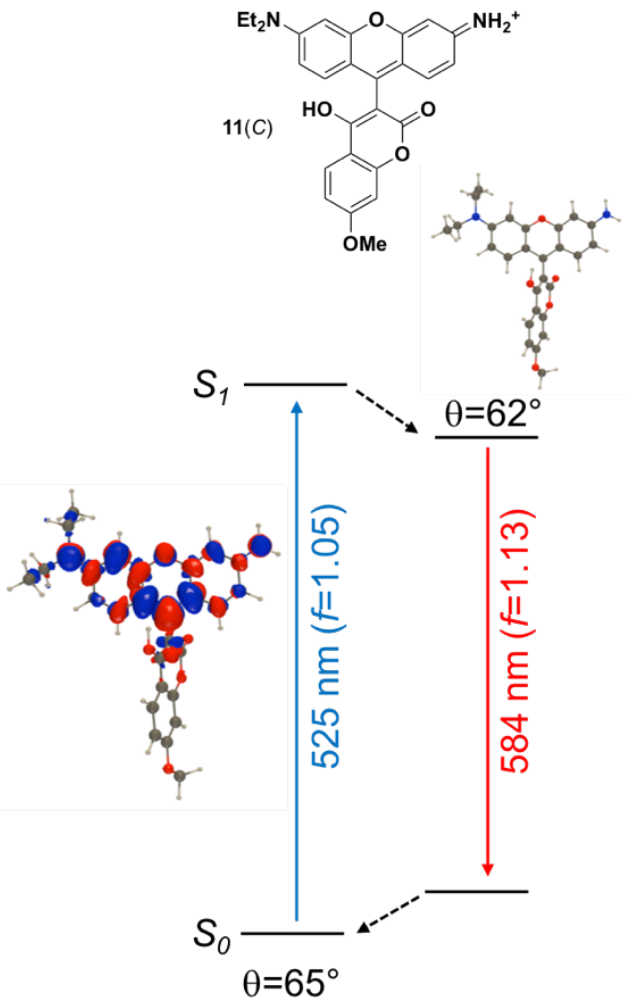

water

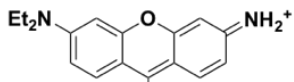

11(Z)

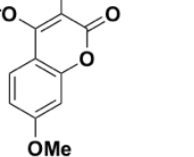

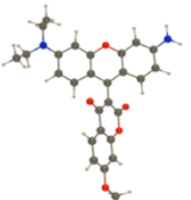
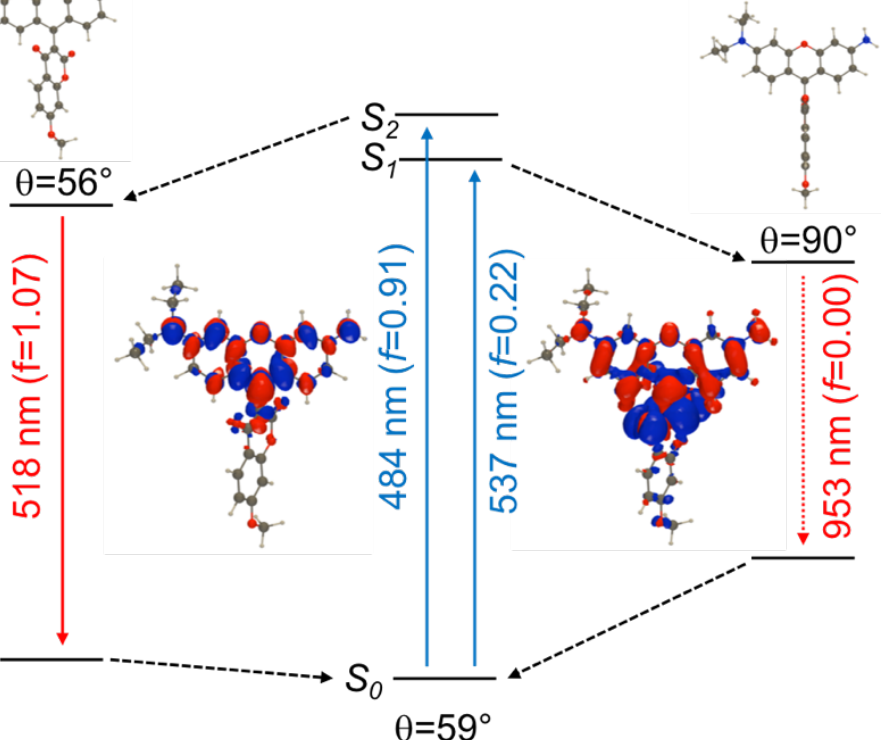

Figure 6. Computed photophysical results for $\mathbf{1 1}(C)$ in $\mathrm{CHCl}_{3}$ (left) and $\mathbf{1 1}(Z)$ in water (right). We show the $\mathrm{CC} 2$-corrected computed vertical transition wavelengths (aqua: absorption, salmon: emission, both in $\mathrm{nm}$ ) and TD-FT oscillator strengths, together with the dihedral angle between the coumarin and pyronin moieties for the various optimal geometries ( $\theta$ in degrees) and the density difference (EDD) plots corresponding to the absorption. In these EDD (contour threshold: $0.001 \mathrm{au}$ ), the blue and red lobes indicate regions loosing and gaining density upon photoexcitation, respectively. Please note: the arrow on the right-hand side is dotted to indicate that such emission is impossible experimentally. 


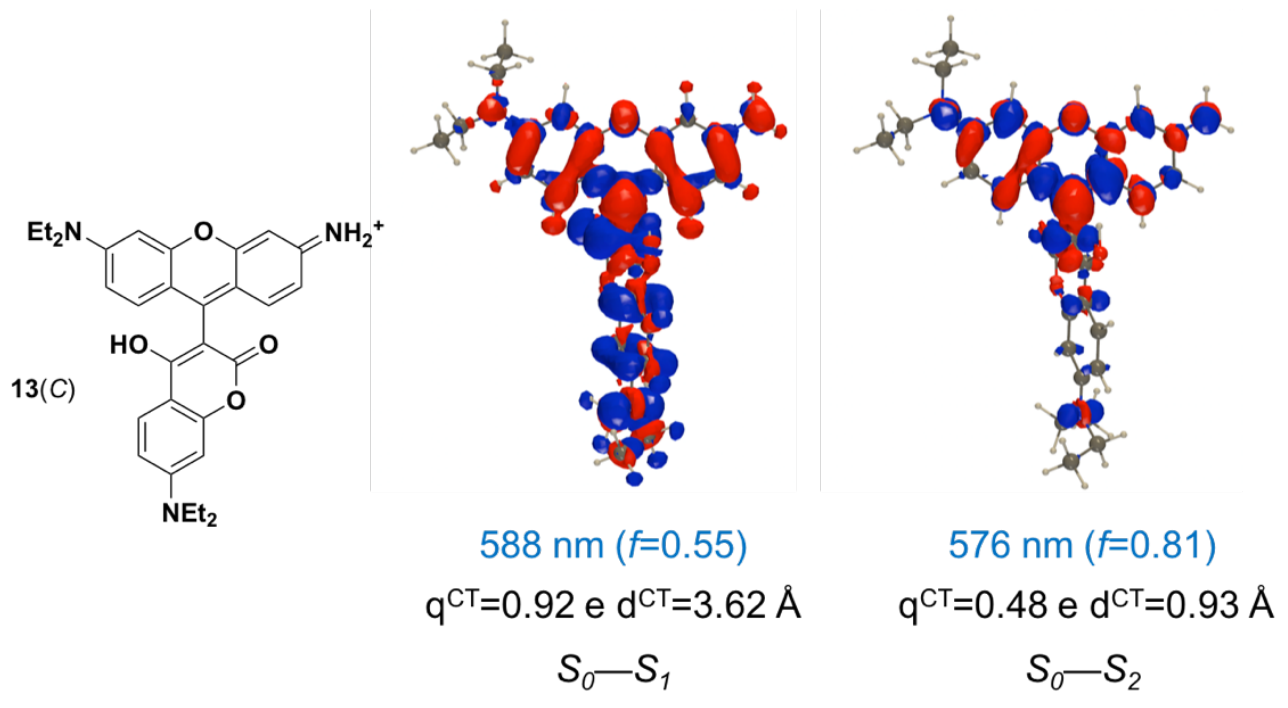

Figure 7. (Left) Cationic form 13(C) of rosamine 13; (right) EDD plots (contour threshold: 0.001 au, see also caption of Figure 6), computed vertical transition wavelengths and CT features for the two lowest transitions in $\mathbf{1 3}(\mathrm{C})$ in $\mathrm{CHCl}_{3}$. See also Figure $\mathrm{S} 19$ in the Supporting Information. 


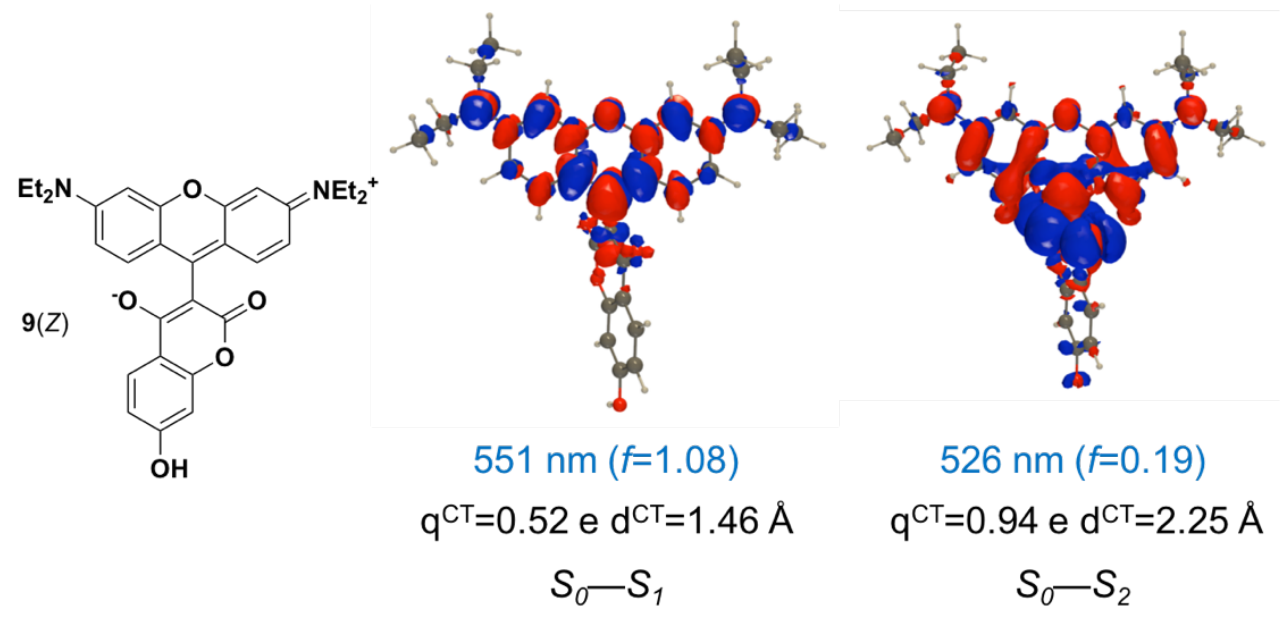

Figure 8. (Left) Zwitterionic form $9(Z)$ of rosamine 9; (right) EDD plots (contour threshold: 0.001 au, see also caption of Figure 6), computed vertical transition wavelengths and CT features for the two lowest transitions in $\mathbf{9}(Z)$ in water. 

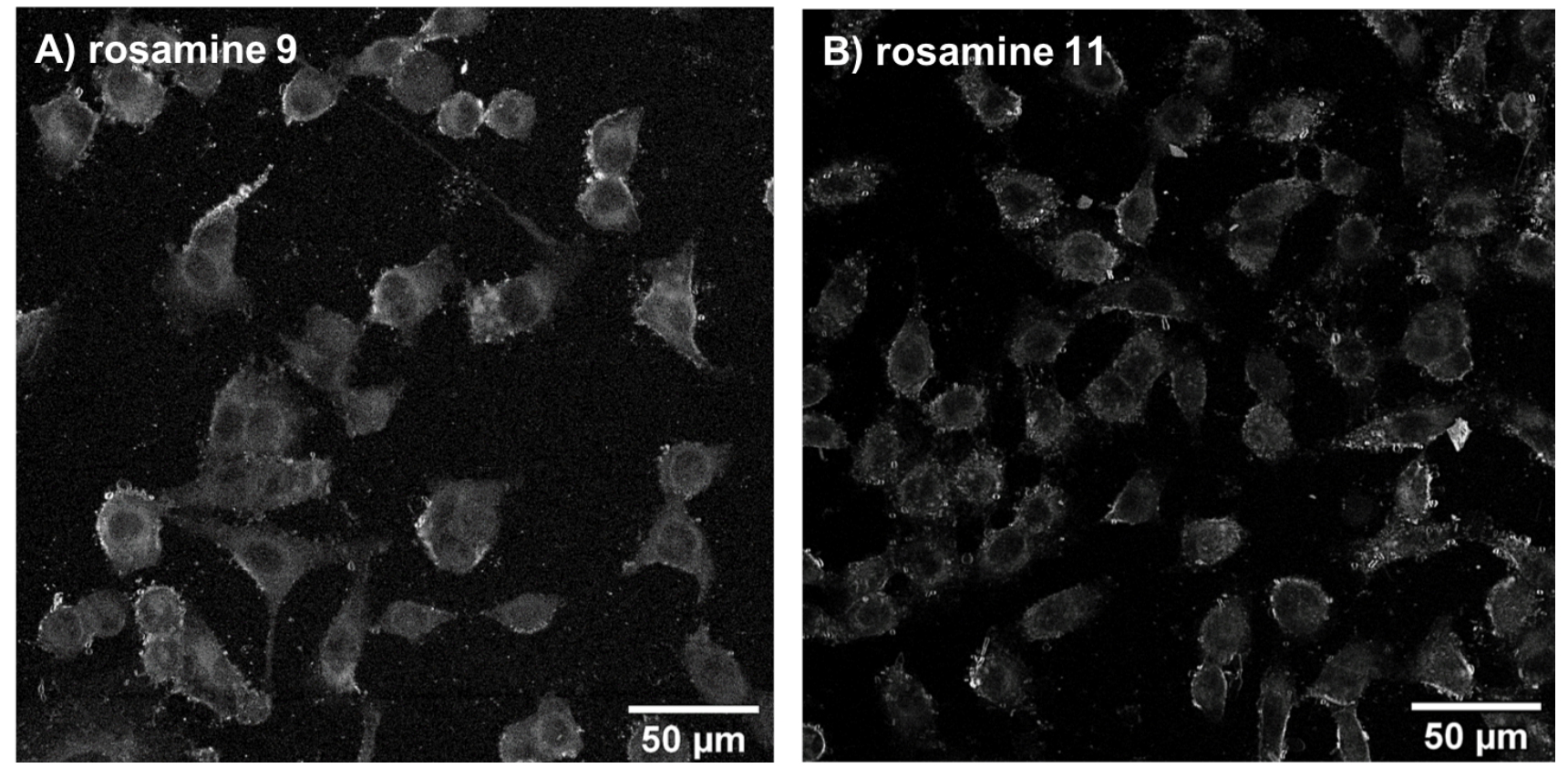

Figure 9. Confocal fluorescence images (gray scale) of fixed A549 cells incubated with fluorophores 9 and 11 (5 $\mu \mathrm{M})$ for 2 h. (A) rosamine 9, $\lambda_{\mathrm{Ex}} 560 \mathrm{~nm}$; $\lambda_{\mathrm{Em}}: 580-670 \mathrm{~nm}$; (B) rosamine 11, $\lambda_{\mathrm{Ex}} 540 \mathrm{~nm}$; $\lambda_{\mathrm{Em}}: 560-650 \mathrm{~nm}$ scale bars: $50 \mu \mathrm{m}$. 